\title{
Dystrophins, Utrophins, and Associated Scaffolding Complexes: Role in Mammalian Brain and Implications for Therapeutic Strategies
}

\author{
Caroline Perronnet $^{1,2}$ and Cyrille Vaillend ${ }^{1,2}$ \\ ${ }^{1}$ Univ Paris-Sud, Centre de Neurosciences Paris-Sud, UMR8195, Orsay, 91405, France \\ ${ }^{2}$ CNRS, Orsay, 91405, France \\ Correspondence should be addressed to Caroline Perronnet, caroline.perronnet@u-psud.fr
}

Received 16 December 2009; Accepted 14 March 2010

Academic Editor: Meena Upadhyaya

Copyright (C) 2010 C. Perronnet and C. Vaillend. This is an open access article distributed under the Creative Commons Attribution License, which permits unrestricted use, distribution, and reproduction in any medium, provided the original work is properly cited.

\begin{abstract}
Two decades of molecular, cellular, and functional studies considerably increased our understanding of dystrophins function and unveiled the complex etiology of the cognitive deficits in Duchenne muscular dystrophy (DMD), which involves altered expression of several dystrophin-gene products in brain. Dystrophins are normally part of critical cytoskeleton-associated membrane-bound molecular scaffolds involved in the clustering of receptors, ion channels, and signaling proteins that contribute to synapse physiology and blood-brain barrier function. The utrophin gene also drives brain expression of several paralogs proteins, which cellular expression and biological roles remain to be elucidated. Here we review the structural and functional properties of dystrophins and utrophins in brain, the consequences of dystrophins loss-of-function as revealed by numerous studies in mouse models of DMD, and we discuss future challenges and putative therapeutic strategies that may compensate for the cognitive impairment in DMD based on experimental manipulation of dystrophins and/or utrophins brain expression.
\end{abstract}

\section{Introduction}

When dystrophin was identified as the protein responsible for the X-linked Duchenne muscular dystrophy (DMD) syndrome [1], we were far from expecting a role for this protein in a variety of tissues including the central nervous system (CNS). Dystrophin is a large $427-\mathrm{kDa}$ cytoskeleton-associated membrane-bound protein, in which loss-of-function in striated muscles results in membrane instability with progressive, severe, and fatal muscle degeneration in about $1 / 3000$ newborn males. Dystrophin is a key component of multiprotein complexes (dystrophinassociated glycoprotein complex, or DGC) located at the plasma membrane in both muscle and nonmuscle tissues, which mediate interactions between the cytoskeleton, cell membrane, and extracellular matrix (ECM). DGCs are involved in signaling pathways that regulate the structural organization of specialized membrane-contact zones, in particular the clustering of ion channels and postsynaptic membrane receptors during synaptogenesis. The presence of dystrophin and DGC in central synapses in brain regions involved in cognitive functions suggests that loss-of-function may be responsible for the cognitive deficits and mental retardation associated with DMD.

Two decades of research significantly increased our understanding of dystrophin function and unveiled the complex etiology and multisystemic aspect of the brain and cognitive alterations in DMD. The rapid development of molecular tools and antibodies directed against specific domains of the protein led to the discovery of an array of dystrophin-gene products. In brain, each of these dystrophins is expressed from distinct internal promoters in either neurons or astrocytes and is component of distinct DGCs selectively involved in synapse or blood-brain barrier (BBB) functions. While the loss of full-length dystrophin is a common feature in all DMD patients and may explain some of the mild deficits displayed across intellectual levels [2], the presence of mental retardation in a subpopulation of 
patients likely results from mutations affecting expression of shorter dystrophin-gene products derived from downstream promoters, such as Dp140 and Dp71 [3]. One main challenge to understand the clinical heterogeneity in DMD is to decipher the specific roles of the different dystrophins in the genesis of cognitive impairments. Moreover, a large number of dystrophin paralogs encoded by distinct autosomal genes, such as the utrophin-gene products, have also been characterized in CNS, thus showing that dystrophins are members of a large and complex superfamily of membrane-bound cytoskeletal proteins. While these paralogs are not directly involved in known genetic diseases, they likely subserve important cellular functions and may offer new prospects in the search of compensatory strategies to alleviate the cognitive phenotype in DMD.

This review summarizes our current knowledge of the structural and functional properties of dystrophins, utrophins and DGCs in brain, as well as the mechanisms by which they participate to the genesis of brain and cognitive alterations in DMD. A detailed description of their expression and/or function in muscles, retina, or invertebrate nervous system falls outside the scope of the review and can be found elsewhere [4-6]. Rather, in the following discussion we will first detail the cognitive profile of DMD patients and the genotype-phenotype relationships linking cognitive impairments to brain dystrophins. Then we will focus on the main structural and functional commonalities and differences between the dystrophin-gene and utrophin-gene products in the mammalian brain, as this may be relevant for therapeutic strategies. We will detail how recent studies of dystrophins loss-of-function in mouse models of DMD have led to a broader understanding of the neurobiology of the disease, and for the utrophin-gene products, we will show how analyses of their structure, their interactions with the DGC, and their cellular and subcellular distribution helped proposing hypotheses on their function in brain tissues. In the last part of the discussion we will describe the recent advances made to treat muscle pathology in DMD, mostly based on the manipulation of dystrophins and utrophins expression, and we will highlight the future challenges and therapeutic strategies that may help translating these approaches to alleviate the cognitive impairment in DMD.

\section{The Cognitive Impairment in DMD}

DMD is associated with nonprogressive mild to severe cognitive deficits and poor academic achievement, which are independent from the muscular handicap or clinical environment [7]. Full-scale intelligence quotient (IQ) scores of DMD patients are distributed normally, in accordance with the assumption that the cognitive defect results from the same mutations that cause myopathy. However, a one standard-deviation leftward shift of the distribution results in a reduced mean IQ (80-85) compared to the normal population mean of 100 [8]. In fact, about one third of DMD boys have IQ scores below 70 and display mental retardation (MR). Deficits affect both receptive and expressive language skills, with alterations in auditory comprehension, phonological knowledge and language, and delayed acquisition of reading, which has been partly attributed to a form of developmental dyslexia, that is, dysphonetic dyslexia [9]. Impaired short- and long-term memory performances are consistently reported and include defective recall, working memory, memory span, and visuospatial skills $[2,7,10,11]$. Recent studies emphasized the high incidence of various neuropsychiatric disorders, such as autism spectrum, attention deficits, hyperactivity, and obsessive-compulsive disorders [12], depression and anxiety symptoms [10], as well as social behavior problems and poor recognition of facial affect [13-15]. Thus, DMD involves a range of neurobehavioral disturbances likely related to functional alterations in integrated brain circuits including the cerebellum, hippocampus, and associative cortical areas [16], in line with dystrophins expression patterns in brain [17].

\section{Genotype-Phenotype Relationships}

It is admitted that the cognitive impairments in DMD have a genetic basis and that the site of mutations in the dystrophin gene determines the risk of cognitive deficit. Genotype-phenotype relationships were initially based on reports showing that deletions of exon 52 [18] and mutations affecting the carboxyl terminus of dystrophin [19] were associated with mental retardation. Conclusions from both clinical and animal-model studies then converged to the current hypothesis that all dystrophins expressed in brain likely contribute to the cognitive and behavioral alterations in DMD. The presence of moderate but specific memory and attention deficits in all DMD patients, regardless of whether they are of high or low intellectual function [2], suggests a role for the full-length (Dp427) dystrophin which is commonly lost in all patients. However, mutations affecting the genomic region of Dp71 and Dp140 have been associated with higher incidence and most severe profiles of cognitive alterations [20-22], and these short C-terminal dystrophins have thus emerged as major contributing factors to the genesis of mental retardation. The most recent studies using large cohorts of patients and fine classifications of subphenotypes and dystrophin products confirm these hypotheses: Mutation location determines cognitive disability, but not motor outcomes [3]; loss-of-function of all dystrophin-gene products is systematically associated with severe form of mental retardation with Dp71 loss being a clear aggravating factor [23]; correlations between mutation locations and IQs suggest that the variable degrees of cognitive impairments result from the cumulative loss of the different dystrophin products [24].

Structure-function analyses and functional studies of mouse models of DMD (below) provided an essential contribution to our understanding of the specific brain mechanisms involved in the genesis of the cognitive alterations in DMD. They confirmed the implication of Dp427 and Dp71 in brain and cognitive functions and helped elucidating the selective roles of these distinct dystrophin products in specific brain mechanisms. 


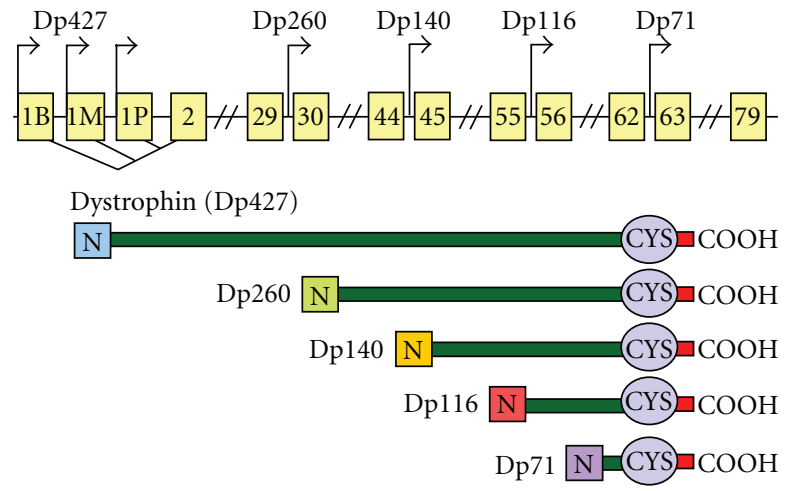

(a)
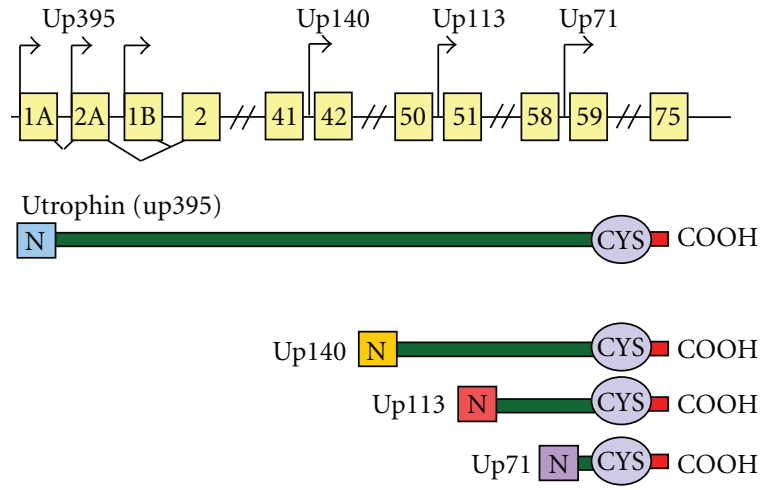

(b)

FIGURE 1: Organization of the human dystrophin (a) and utrophin (b) genes and corresponding protein products. Top panels show specific exons (yellow boxes with exon numbers) and intronic regions (black line) flanking transcription start sites of the different gene internal promoters (arrows) (Source: Pubmed: ENSG00000198947 for DMD gene; ENSG00000152818 for utrophin gene). Alternatively spliced first exons giving rise to distinct full-length forms of dystrophin (B: Brain; M: Muscle; P: Purkinje cells) and utrophin (Utrn-A; Utrn-B) are depicted (adapted from [30]). The different dystrophin (a) and utrophin-gene (b) protein products derived from distinct internal promoters are shown below the corresponding genes, as indicated. The main structural domains are represented, including the specific NH2-terminus domain ( $\mathrm{N}$, different colors schematize distinct NH2-terminal sequences), the central rod domain (green bar), the cysteine-rich domain (CYS, blue), and the COOH-terminus (red). All gene regions and protein domains are not to scale.

\section{Structure and Expression of the Dystrophin-Gene Products}

In DMD, the majority of mutations, mainly deletions but also duplications, inversions and point mutations, are outof-frame and result in complete loss of dystrophin or expression of nonfunctional truncated proteins. However, some internally truncated proteins that only miss some of the repeats of the central domain of dystrophin retain functional activity and are associated with the milder Becker muscular dystrophy (BMD) phenotype, suggesting that different dystrophin structural domains have distinct functions [25]. Key structure-function correlations have been characterized from genotype-phenotype studies in DMD patients (e.g., $[3,26]$ ) and from numerous studies in genetic mouse models of DMD, including forced expression of truncated dystrophin constructs in dystrophin-deficient mice (e.g. [27]).

4.1. The Full-Length Dystrophin (Dp427). The DMD or dystrophin gene, identified by positional cloning and localized to $\mathrm{Xp} 21$, is the largest described, spanning $\sim 2.5-\mathrm{Mb}$ with 79 exons encoding a $14 \mathrm{~kb}$ mRNA transcript. This full-length mRNA and the corresponding 427-kDa protein, called dystrophin or Dp427, are predominantly expressed in skeletal and cardiac muscles and to a lesser extent in the nervous system. Dystrophin structure is organized in four main domains (Figure 1) $([4,28,29]$ for reviews). The N-terminal domain (246 amino-acids) similar to $\alpha$-actinin contains several actin-binding sites and a calmodulin-binding site. The central rod domain (2840 aa) has 24 triple-helical spectrinlike repeats thought to give the protein a flexible structure, with several irregular short and long segments, and four proline-rich end regions. As deletions of this region often result in mild or no clinical consequences, it is sometimes simply considered as a spacer between the actin-binding domain and the next cysteine-rich and $\mathrm{COOH}$-terminal domains. These latter are of high functional relevance as they interact with several membrane-bound and cytosolic proteins that form the DGC (Figure 2): the cysteine-rich domain (280 aa) participates in the critical interaction of dystrophin with the transmembraneous DGC component, $\beta$-dystroglycan. It starts with a WW domain described as a protein-binding module, followed by two calcium-binding EF-hand motifs and a zinc-finger ZZ domain representing a functional calcium-dependent binding site for calmodulin. The COOH-terminus (320 aa) is an $\alpha$-helical coiled coil region that binds to the cytosolic component dystrobrevin and may also modulate interactions with syntrophins and other DGC-associated proteins.

Several phosphorylation sites have been identified within dystrophin structural domains, suggesting regulation of actin binding by endogeneous protein kinases (PK) such as PKA, PKC, calmodulin kinase II (CamKII), and casein kinase II (CKII) [31-33], while interactions with the DGC and signaling proteins could be modulated by CamKII, CKII, MAPK, cdc2, and GSK-3 [34-36].

\subsection{Tissue-Specific Promoters Drive Expression of Distinct Dys-} trophins. At least seven internal promoters enable expression of several dystrophin-gene products in a tissue and cell-specific manner (Figure 1). Dp427 is derived from three independent promoters $(\mathrm{M}, \mathrm{B}$, and $\mathrm{P})$ consisting of spliced unique first exons that regulate the spatiotemporal expression of this full-length protein in muscles, forebrain structures, and cerebellar Purkinje cell, respectively. In adult skeletal muscle, Dp427 is located at the sarcolemma and in the troughs of the postsynaptic membrane. Its loss is associated with disruption of membrane integrity, protease 


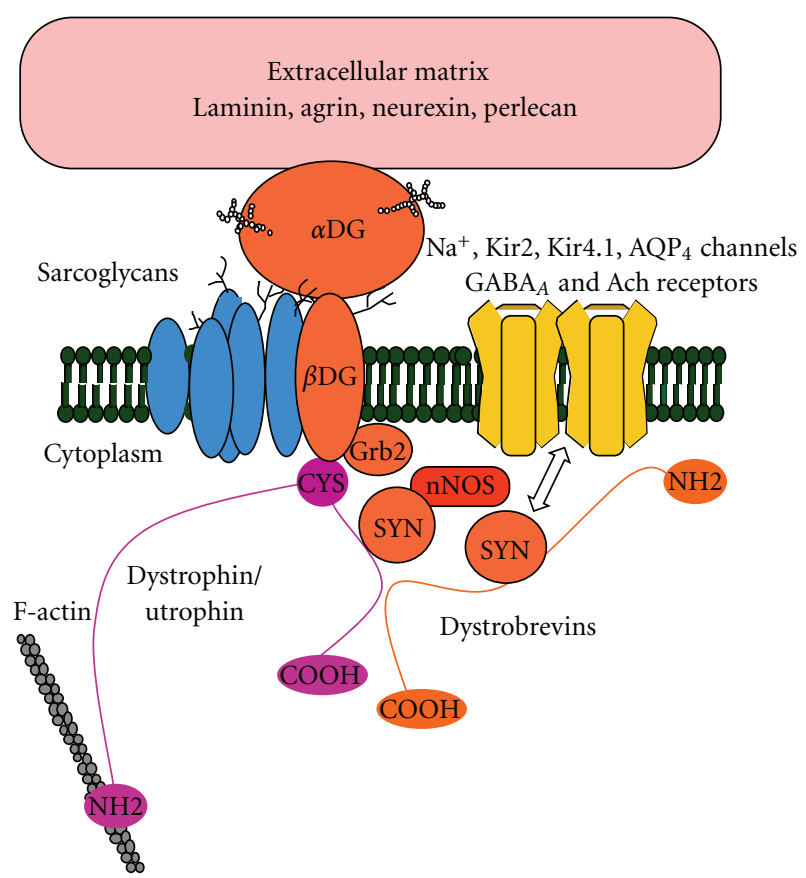

FIGURE 2: Organization and composition of the dystrophin/utrophin-associated glycoprotein complexes (DGC/UGC). The NH2terminus of dystrophins and utrophins (purple) binds to cytoskeletal filamentous actin (F-actin) while the cysteine-rich and $\mathrm{COOH}$ domains interact with the different DGC/UGC components. The cysteine-rich domain binds the dystroglycan subcomplex composed of transmembrane $\beta$-dystroglycan $(\beta$-DG) and extracellular $\alpha$-dystroglycan $(\alpha$-DG). The $\beta$-dystroglycan may interact with the sarcoglycan-sarcospan subcomplex (blue) and with signaling protein such as Grb2. The $\alpha$-DG is a glycosylated receptor for extracellular matrix proteins, such as laminin, agrin, perlecan, and neurexin depending on tissue- and cell-specific expression. The COOH-terminus of dystrophins/utrophins binds the cytosolic proteins syntrophins and dystrobrevins. Dystrobrevins associate with syncoilin, dysbindin, and syntrophins (SYN). Syntrophins contain a PDZ domain enabling associations of the DGC with a variety of proteins including signaling and synaptic proteins, such as neuronal nitric oxide synthase (nNOS) or neuroligins, as well as several transmembrane channels (AQP-4, potassium Kir2 and Kir4.1, and voltage-gated sodium channels) and receptors (AchR, $\left.\mathrm{GABA}_{\mathrm{A}} \mathrm{R}\right)$.

activation, calcium inflows, and altered calcium homeostasis leading to progressive muscle necrosis and wasting (reviewed in $[4,37]$ ). In brain and cerebellum, Dp427 is mainly detected along plasma membranes in the soma and in the postsynaptic densities (PSDs), specialized regions of the synapse submembraneous cytoskeleton of principal neurons. Several studies provided evidence for major expression in brain regions involved in motor, emotional, and cognitive functions ([38] for a review), such as the hippocampus, neocortex, cerebellum, and amygdala, whereas little or no dystrophin could be detected in other subcortical regions such as striatum, thalamus, and hypothalamus $[17,39,40]$. Therefore, Dp427 loss-of-function is a common feature in all DMD patients that may result in both muscle degeneration and altered brain function.
Four shorter nonmuscle products expressed from downstream promoters have been characterized, which in common with Dp427 harbor at least the cysteine-rich and $\mathrm{COOH}$-terminal domains. They have been named according to their respective molecular weights: Dp260 (Dystrophin protein of $260 \mathrm{kDa}$ ) is found in the outer plexiform layer in the retina and its dysfunction is associated with alterations of the electroretinogram and of color vision [41, 42]. Dp140 is detected in kidneys, retina, and brain; it is abundant in fetal brain tissues and is thought to be essentially expressed in astrocytes and/or microvasculature [43,44]. Dp116 is mainly expressed in Schwann cells in spinal cord [45], yet it has also been detected in brain PSDs [46]; The short Dp71 product is transcribed from a promoter located between exons 62 and 63 and has a unique $\mathrm{N}$-terminus of seven amino acids. It is detected in cardiac muscle and in most nonmuscle tissues including brain, retina, kidney, liver, and lung. It is the most abundant DMD-gene product in adult CNS, mainly detected around brain blood vessels in perivascular astrocyte endfeet [47], suggesting a role in BBB function. Dp71 mRNA is also detected in neurons in olfactory bulb and in the dentate gyrus of the hippocampus [48]; the protein is found in cultured neurons [49] and in the PSDs of central synapses in the adult brain $[50,51]$, suggesting an additional role in synaptic function.

Expression of DMD-gene products also appears to be modulated during development and in different tissues by alternative splicing at the $3^{\prime}$ end of the gene, which generates an even greater number of dystrophin isoforms [52]. Splicing preferentially affects four tandems of exons (71-74) and exon 78 in Dp427, Dp140, and Dp71 [28, 53-57]. While all DMD-gene products retain functional cysteine-rich and $\mathrm{COOH}$-terminal domains and can therefore interact with the DGC, the splicing of exons 71-74 seems to be of functional importance as it likely modulates the capacity of dystrophins to bind specific components of the DGC such as syntrophins $[51,58]$.

Thus, the dystrophins constitute a family of cytoskeleton proteins with multiple products of various molecular weights and spliced variants, each of which is a central component of a membrane-bound molecular scaffold. These proteins have specific sequences but high structural homologies and may therefore endorse cell-specific roles as well as common biological functions.

\section{Structure and Expression of Dystrophin-Related Proteins}

Dystrophins share structural homology with a range of paralog proteins called the dystrophin-related proteins, such as utrophin, DRP2, dystrobrevin, and dystrotelin [59]. The utrophin family of proteins has been most studied due to its involvement in skeletal muscle development and function at the adult neuromuscular junction (NMJ). Because different utrophin-gene products derive from distinct internal promoters in a variety of tissues, as for expression of the different dystrophin-gene products, their potential role in compensating dystrophin deficiency in DMD has yielded much interest in recent research. 
5.1. The Full-Length Utrophin. This autosomal protein was identified in 1989 [60] due to its large homology with dystrophin, and it was named utrophin because of its ubiquitous tissue expression as compared to dystrophin [61]. The gene is localized on human chromosome 6q24 [62] and on mouse proximal chromosome 10 [61]. This large $900 \mathrm{~kb}$ gene encodes a $13 \mathrm{~kb}$ transcript of 74 exons that predicts a full-length protein of $395 \mathrm{kDa}$, which is therefore smaller than dystrophin. The primary sequence and protein structure show large and clear similarities with dystrophin. The N-terminal domain encompasses the first 250 aa and binds F-actin with a similar affinity as dystrophin. Although being larger and more effective than the dystrophin actinbinding domain [63], its structure is also comparable to that of spectrin and alpha-actinin and the actin-binding process is regulated by calcium and calmodulin. Along with the cysteine-rich and $\mathrm{C}$-terminal domains, this region shares $80 \%$ of identity with the equivalent domain of dystrophin. The large rod domain is the least conserved region between the two proteins (35\%) (reviewed in [64]), consisting of 22 spectrin-like repeats in utrophin, versus 24 repeats in dystrophin, and proline-rich hinge regions. The utrophin C-terminal domain is very similar to that of dystrophin with typical binding to the different DGC members, $\beta$ dystroglycan, $\alpha$-dystrobrevin, and the syntrophins $[4,5]$.

Like dystrophin, the utrophin gene harbors tissuespecific promoters (Figure 1). Transcription of the fulllength utrophin (Up395) is driven by two independent promoters, Utrn-A and Utrn-B, coactivated in a number of tissues but independently regulated. The TATA-box less Utrn-A promoter is associated with a $\mathrm{CpG}$ island and contains a consensus N-box at the $5^{\prime}$ end of the transcript [65]. The Utrn-B promoter is located in intron 2 of the gene [66]. Each promoter induces a spliced unique first exon but both promoters drive expression of 13-kb mRNAs which only differ within the $5^{\prime}$-end region.

The Utrn-A protein is the main isoform in adult skeletal muscles, enriched at the crest of postsynaptic-membrane folds in association with acetylcholine receptors (AchR) at the NMJ. In contrast, Utrn-B is found in muscle vascular endothelium $[67,68]$. Obviously, dystrophin and utrophin display distinct subcellular localization in adult-striated muscles. However, utrophin expression occurs before that of dystrophin in developing and regenerating muscle, where it is detected along the muscle sarcolemma [69]. At birth and/or in mature muscle, utrophin is then replaced by dystrophin along the sarcolemma and its expression remains confined to NMJ and vasculature [70]. For this reason, utrophin has been considered a foetal dystrophin homologue in developing muscle tissues, suggesting that the two proteins could share common functions in muscle structure and/or physiology.

Full-length utrophins are also detected in nonmuscle tissues, such as in the CNS, peripheral nerves, testis, kidney, spleen, liver, lung, platelets, and in small arteries and veins [71-74]. They are found in both blood vessels and neurons in the adult brain $[75,76]$ and in Müller glial cells in the retina [77]. In neurons, utrophin labelling is localized along the somatic and dendritic membrane, which is at variance with the punctuate synaptic staining revealed by antidystrophin antibodies in synapses [39, 76]. The respective distributions of Utrn-A and $B$ in the brain have been recently specified [78]: Utrn-A is mainly found in neuronal cells in various brain structures including olfactory bulb, cortex, medial septum, hypothalamus, hippocampus, cerebellum, and brainstem nuclei; it is also detected in pia mater of the meninge, choroid plexus, ependymal lining, and in some glial cells and vascular structures. Utrn-B is expressed to a lesser extent in the same brain regions and seems enriched in vascular elements.

5.2. The Short Utrophin-Gene Products. As for the DMD gene, the utrophin gene has internal promoters and shorter protein products (Figure 1) and is also modulated by alternative splicing $[79,80]$. G-utrophin, or Up113, was the first short product identified as a structural homologue of Dp116. Its $5,5 \mathrm{~kb}$ transcript predicts a protein composed of the last two and a half coiled-coil repeats of the rod domain, followed by the cysteine rich and C-terminal domains of utrophin. Up113 mRNA differs from that of utrophin at the same point that Dp116 diverges from dystrophin, that is, intron 55. Up113 and Dp116 share a consensus phosphorylation site for PKC in the N-terminal domain [79]. Up113 is the major product of the utrophin gene in the adult brain, but it is also found in the sensory ganglia, testis, and kidney. The brain transcript was detected in blood vessels and in some classes of neurons in accessory olfactory bulb, cerebral cortex, hippocampal formation, brainstem nuclei, amygdala, hypothalamus, thalamus, and caudate putamen $[39,79]$.

Up140 and Up71 are homologous to the short dystrophins Dp140 and Dp71. They depart from Up395 at the same point Dp140 and Dp71 diverge from Dp427. No actin-binding sites have been characterized in the N-terminal domain of these proteins, but ability for protein-protein interactions is preserved [80]. Up71 is translated from a $4 \mathrm{~kb}$ mRNA commencing in intron 58 and detected in lung, muscle, kidney, thymus, liver, and brain. The $71 \mathrm{kDa}$ protein displays the same cysteine-rich and C-terminal domains as Up395 and is detected in peripheral nerve [81]. Up140 derives from a $6,75 \mathrm{~kb}$ mRNA commencing in intron 41 and detected in lung, muscle, kidney, thymus, liver, testis, and brain. The $155 \mathrm{kDa}$ protein comprises the last 6 repeats of the distal rod domain, the cysteine-rich, and the C-terminal domains of Up395. The function of Up71 and Up140 in brain is unknown.

A short $\mathrm{N}$-terminal utrophin, called $\mathrm{N}$-utrophin, was described in C6 glioma cells [82]. It is translated from a $3,7 \mathrm{~kb}$ transcript that predicts a $62 \mathrm{kDa}$ protein. This protein contains the actin-binding domain and two spectrin-like repeats. Expression in mammalian tissues has not been demonstrated to date. Other short utrophins have been reported, such as Up90 in testis, spleen, and liver, Up97 in testis, Up 109 in the foetal hand and foot dermis, Up103 in adult testis, and Up120 in kidneys [73, 83].

The presence of short utrophin-gene products with largely similar structures as compared to dystrophins suggests that duplication of a common ancestor gene might 
have occurred after the appearance of the internal promoters. However, the dystrophin and utrophin genes diverge in their sequences and specificities, which results in nonoverlapping expression patterns [59]. Strikingly, dystrophin and utrophin paralogs are generally expressed in distinct brain structures and cell types, suggesting discrete functions despite high structural homologies.

5.3. The Other Paralogs. DRP2 and dystrobrevin share homology with the carboxy-terminal regions of dystrophins and utrophins. The DRP2 gene is localized to Xq22 and encodes a $7,7 \mathrm{~kb}$ transcript corresponding to a $110 \mathrm{kDa}$ protein. Its sequence shares similarity with the cysteinerich domain and with the $3^{\prime}$ end of the spectrin-like repeat domain of Dp116 and Up113 [84]. DRP2 is mainly expressed in the CNS in association with PSDs and cholinergic neurons [85] and is also detected in the peripheral nervous system [86]. Dystrobrevin is both a dystrophin paralog and a component of the DGC (see below, [87]). The dystrotelin gene maps on mouse chromosome 1 and human chromosome 2 ; it encodes a $74-\mathrm{kDa}$ protein that shares homology with dystrophin and is expressed in the embryonic brain and neural tube [59].

\section{The Utrophin and Dystrophin-Associated Glycoprotein Complexes}

Dystrophin is a key component of the so-called dystrophinassociated glycoprotein complexes (DGC) (Figure 2) formed by at least ten partners encoded by autosomal genes, including transmembrane (dystroglycans) and cytoplasmic (syntrophins, dystrobrevins) proteins that link the actinbased cytoskeleton to the basal lamina in muscles, thus providing a molecular bridge connecting the inside of the cell to the extracellular matrix $(\mathrm{ECM})([4,29,88]$ for reviews). First identified in association with Dp427 in muscle tissues, the DGC interacts with all DMD-gene products as well as with paralogs of the utrophin family. Emerging notion conceptualizes the DGC as a scaffold for proteins involved in membrane stabilization and transmembrane signaling in a variety of tissues and cell types, including the postsynaptic membrane of neurons in CNS $([5,89,90]$ for reviews). However, DGC components are differentially distributed in distinct brain cell types, where they form separate dystrophin-like complexes that likely harbor distinct functions (e.g., [50]).

The central part of the DGC is the dystroglycan subcomplex, composed of $\alpha$-dystroglycan, an extracellular glycoprotein of $156 \mathrm{kDa}$ in muscles and $120 \mathrm{kDa}$ in brain, and $\beta$-dystroglycan, a $43-\mathrm{kDa}$ membrane-spanning glycoprotein which associates with the cysteine-rich domain of dystrophins and utrophins. The two proteins are processed from a precursor protein produced by the dystroglycan gene. This subcomplex is functionally crucial since knocking out the gene results in lethality [91], while conditional knock-out mice revealed impaired synaptic plasticity in the hippocampus, a major brain region involved in cognitive function [92].
The $\alpha$-dystroglycan is a receptor for ECM proteins, such as laminin ( $\alpha 1$ and $\alpha 2$ chains) in striated muscles in association with Dp427, agrin at the NMJ with utrophin, neurexins in the CNS with brain Dp427, and most likely other forms of laminin, perlecan and agrin in brain. Genetic loss or defective glycosylation of brain $\alpha$-dystroglycan abolishes its binding activity to extracellular ligands, which results in critical alterations of the basement-membrane and abnormal neural migration during development. Hypoglycosylation of $\alpha$ dystroglycan due to mutations in specific glycosyltransferases leads to the Walker-Warburg (WWS), Fukuyama (FCMD), and muscle-eye-brain (MEB) syndromes, collectively known as autosomal recessive congenital muscular dystrophies (CMDS). These dystroglycanopathies result in a total disorganization of the cortex associated with mental retardation ([93] for a review).

In muscles, $\beta$-dystroglycan binds calveolin-3 and an adaptor protein called growth factor receptor-bound protein 2 (Grb2), suggesting participation in transduction of extracellular-mediated signals. Grb2 may also regulate interactions between $\beta$-dystroglycan and other partners of the DGC in other tissues, such as with rapsin during synaptogenesis at the NMJ [94], and with the focal adhesion kinase (FAK) in the CNS [95], a nonreceptor tyrosine kinases involved in neurite outgrowth, dendritic spine morphogenesis, and synaptic plasticity.

The muscle sarcoglycan subcomplex is composed of four transmembrane glycoproteins, $\alpha-, \beta-, \gamma_{-}$, and $\delta$ sarcoglycans, which form heterotetrameric complex associated with dystroglycan and with a member of the tetraspan family of proteins called sarcospan. Original findings suggested selective expression in muscles and peripheral nerves. However, recent studies revealed the existence of new members of the sarcoglycan family in brain, $\mathcal{E}$-sarcoglycan involved in myoclonus-dystonia syndrome and associated with dopaminergic neurons, and $\zeta$-sarcoglycan. Whereas mutations affecting sarcoglycans lead to severe forms of muscular dystrophy, suggesting an important role in membrane stability, their organization, function, and interaction with the brain DGC remain unclear (reviewed in [90]).

Dystrobrevins and syntrophins are cytosolic components of the DGC. Dystrobrevins are proteins of $87-94 \mathrm{kDa}$ that are both dystrophin paralogs, due to their structural homologies with the C-terminus of DMD-gene products, and dystrophin-associated proteins due to their direct binding to the dystrophin/utrophin C-terminus through coiledcoil motifs. The $\alpha$ - and $\beta$-dystrobrevins, encoded by two separate autosomal genes, occur as various isoforms in many DGC-like complexes in both muscle and nonmuscle tissues. Dystrophins and dystrobrevins can bind up to four syntrophins, which in turn interact with a variety of key membrane proteins (see below). Several other dystrobrevinbinding proteins have been characterized, such as syncoilin, dysbindin, and neuronal kinesin heavy chain 5A. The dysbindin protein yielded much interest in recent research [96], as it is produced by a schizophrenia-susceptibility gene. It is a partner of the biogenesis of lysosome-related organelles complex-1 (BLOC-1) thought to regulate the trafficking and assembly of the brain DGC, and it is a potential regulator 
of the synaptic vesicle cycle in central glutamatergic synapses $[97,98]$.

Syntrophins are $59 \mathrm{kDa}$ adaptor proteins occurring as $\alpha$ , $\beta 1, \beta-2, \gamma-1$, and $\gamma-2$ isoforms. They contain a PDZ domain enabling associations with a variety of proteins involved in critical cellular functions in CNS (reviewed in [90]), including neuronal nitric oxide synthase (nNOS) and many transmembrane proteins, such as the water aquaporin4, potassium Kir2 and Kir4.1, and voltage-gated sodium channels, as well as synaptic proteins like neuroligins, calmodulin, and erbB-4 neuregulin receptors. Interactions of the DGC with the scaffolding protein PSD-95 may occur in neurons, due to the association of nNOS with this protein. The potential binding of several syntrophins to one DGC suggests that several of such interactions may occur simultaneously in specific tissues or cell types, which places syntrophin as a major player in the membrane organization and signaling functions of brain DGC.

Much has been learned about DGC functions from studies of the mammalian NMJ, where the DGC accumulates in association with utrophin at the postsynaptic side during early postnatal development and appears to be involved in the process of neuromuscular synaptogenesis [94]. The current model considers that agrin-mediated clustering of AchR via muscle-specific tyrosine kinase MuSK does not require the DGC. However, secondary interactions of DGC with rapsyn, an effector protein of MuSK, seem to be required for AChR stabilization and synapse maturation, as in mouse models lacking dystroglycan, utrophin, $\alpha 1$ syntrophin, or $\alpha$-dystrobrevin, the density of AChR clusters is reduced at the NMJ [99-104]. Analogies to this model have been recently evidenced in the CNS (see next section), suggesting a general biological role for the DGC, in association with distinct dystrophins and utrophins, in the stabilization rather than targeting of membrane proteins during the maturation and maintenance phases of synaptogenesis [89]. Despite much similarities between the utrophin-glycoprotein complex (UGC) and the DGC, functional differences have been pointed out by several studies [105-107]. One example is the gliovascular interface, where a specific Dp71-DGC is expressed in the perivascular astrocyte endfeet, whereas distinct UGC components associate with utrophin in the facing endothelial cells. Both complexes may play a role in BBB function. However, selective ablation of utrophin or Dp71 only disrupts the corresponding UGC or DGC, without affecting the complex associated with the remaining paralog [47], suggesting distinct functions for these separate dystrophin-like complexes.

\section{Role of Dystrophins in the Mammalian Brain}

The genesis of cognitive deficits in DMD likely involves cumulative inactivation of Dp427, Dp71, and Dp140. One main goal of the past two decades has been to define the genotype-phenotype correlations in patients and to specify the localization and function of brain dystrophins. While variable degrees of cognitive dysfunction were found in DMD patients across IQ levels, the mutations affecting Dp71 and Dp140 in addition to Dp427 emerged as aggravating factors leading from moderate to severe mental retardation [3]. Dp140 is abundant in the fetal brain, suggesting a key role during brain development, whereas its presence around blood vessels in the adult brain may play a role in specific yet unidentified vascular-glial interactions $[43,44]$. The function of Dp140 remains unknown and a mouse model with selective disruption of this protein has not been developed to date. In contrast, functional studies in several dystrophin-deficient mouse models have greatly increased our understanding of Dp427 and Dp71 function in brain and uncovered the role of the DGC in critical cellular functions, suggesting that the brain alterations in DMD mainly result from the mistargeting of syntrophin-interacting proteins, including key membrane receptors and channels involved in neuronal and glial functions.

7.1. Full-Length Dystrophin (Dp427) Function. Most of our current understanding of dystrophin function derives from studies of the Dp427-deficient $m d x$ mouse. Although this model lacks the full-length dystrophins in both muscle and nonmuscle tissues, it does not exhibit extensive muscle degeneration during the first 6 months of postnatal life, possibly due to efficient muscle regeneration [108]. $M d x$ mice however display abnormal motor behavior and coordination [109] and reduced activity in open spaces [110]. Whether these deficits result from muscle wasting or rather reflect impaired forebrain or cerebellar functions remains an open question. Noncognitive behavioral disturbance, such as enhanced defensive freezing responses after restraint, has also been shown in $m d x$ mice suggesting altered amygdala function [40]. Although the motor and emotional defects in this model could influence the animal's performance in cognitive tests, analyses of specific behavioral parameters in various paradigms allowed our group to characterize mild but specific memory deficits in $m d x$ mice, part of which likely involves brain structures that include the hippocampal formation. While encoding of new experiences and learning capabilities are globally preserved [111, 112], $m d x$ mice show slower learning in bar-pressing tasks and impaired retention performance at long delays in several tests involving recognition and spatial memories [110, 113116], which suggests a selective role for dystrophin in the consolidation or expression of specific forms of long-term memory.

Given the crucial role of synaptic plasticity in learning and memory processes, the question then arose as to whether altered synaptic function could explain the memory deficits in $m d x$ mice. The early finding that CA1 hippocampal neurons in $m d x$ mice are more susceptible to hypoxia-induced reduction in neurotransmission [117] suggested a critical role for dystrophin in synaptic function. Despite changes in the distribution of neuronal cells in specific cortices [118], we did not find gross histological abnormalities in brains of $m d x$ mice [119]. Current hypotheses consider that the brain alterations are most likely located at the cellular level, and there is now ample evidence that the Dp427-DGC modulates synapse function in brain structures 
expressing dystrophin. In Purkinje cells of cerebellum, $m d x$ mice display reduced heterosynaptic long-term depression (LTD) of neurotransmission [120], whereas homosynaptic LTD is enhanced [121]. In the hippocampus of the $m d x$ mouse, we found that NMDA receptor-dependent short(STP) and long-term potentiation (LTP) as well as LTD are all abnormally enhanced in the CA1 dendritic layer $[110,112,115]$. Hence, there are critical alterations of longterm synaptic plasticity in these two brain regions when dystrophin is missing.

Although various biochemical, physiological, and bioenergetics abnormalities have been reported in brains of $m d x$ mice ([122, 123], for reviews), the main hypothesis to explain brain dysfunctions in $m d x$ mice is an alteration of the inhibitory control of neurotransmission in principal neurons. Indeed, dystrophin and dystroglycan colocalize with $\alpha 2$-subunit of $\mathrm{GABA}_{\mathrm{A}}$ receptors $\left(\mathrm{GABA}_{\mathrm{A}}-\mathrm{R}\right)$ in cultured hippocampal neurons, but their targeting to the membrane is independent from that of $\mathrm{GABA}_{\mathrm{A}}-\mathrm{R}$ and scaffolding protein, gephyrin $[124,125]$. In the adult CNS, dystrophin and DGC are located in a subset of inhibitory synapses. Several studies showed that the loss of dystrophin or dystrobrevins leads to significant reductions in the number and size of $G_{A B A}-R$ clusters in hippocampus [126], cerebellum [109], and amygdala [40]. Different subunits of $\mathrm{GABA}_{\mathrm{A}}-\mathrm{R}$ may be affected in distinct brain structures, for example, $\alpha 1$ in cerebellum and $\alpha 2$ in hippocampus, suggesting that dystrophin is involved in the clustering of subpopulations of $\mathrm{GABA}_{\mathrm{A}}-\mathrm{R}$ at inhibitory synapses. Together the current data suggest that dystrophin is not essential during early GABAergic synaptogenesis but rather stabilizes these receptors at a later stage, perhaps by limiting their lateral diffusion outside the synapse through neurexin-neuroligin dependent signaling [127, 128].

The number of $\mathrm{GABA}_{\mathrm{A}}-\mathrm{R}$ and dystrophin clusters can be modulated in parallel in a model of temporal lobe epilepsy in mice [129], suggesting a concomitant involvement of the two proteins during the type of neural plasticity associated with this pathological environment. However, compelling evidence for functional interactions between dystrophin and $\mathrm{GABA}_{\mathrm{A}}-\mathrm{R}$ is still missing. The hypothesis however gained support from recent electrophysiological studies confirming alterations of inhibitory function in $m d x$ mice. First, the potency of $\mathrm{GABA}_{\mathrm{A}}-\mathrm{R}$ antagonist bicuculline to modulate glutamatergic neurotransmission is reduced in $m d x$ mice, in both cerebellar and hippocampal neurons [130, 131]. In $m d x$ cerebellar Purkinje cells, significant reductions in both the frequency and amplitude of spontaneous miniature inhibitory postsynaptic currents (mIPSCs) have been reported [130, 132], consistent with alterations of postsynaptic $\mathrm{GABA}_{\mathrm{A}}-\mathrm{R}$ function leading to reduced inhibitory input. Studies in CA1 hippocampus provided opposite results, showing increased mIPSCs frequency [133], which suggests a higher probability of inhibitory synaptic release in $m d x$ mice in this structure. Our recent ultrastructural study of CA1 hippocampal synapses revealed an increased number of inhibitory synapses in $m d x$ mice, which may explain higher release probability at these synapses and likely reflects systemic compensation for impaired GABAergic function [119]. A study suggests that the increased number of hippocampal inhibitory synapses results from a compensatory increase in the number of parvalbuminpositive GABAergic interneurons in this structure [134]. We also demonstrated morphometric changes in the PSDs of a subpopulation of excitatory synapses, which may account for the sustained increase in CA1 synaptic efficacy and excitability. Interestingly, we also showed that the enhanced hippocampal STP and LTD in $m d x$ mice could be prevented by bicuculline [131], suggesting a correlation between altered inhibitory function, changes in excitatory synapse morphology, and abnormal CA1 hippocampal synaptic plasticity. Furthermore, $m d x$ mice have altered neuronal excitability induced by AMPA/kainate subtypes of glutamate receptors and increased susceptibility towards PTZ-induced kindled seizures $[135,136]$, suggesting that dystrophin loss and altered $\mathrm{GABA}_{\mathrm{A}}-\mathrm{R}$ clustering globally compromise brain excitatory/inhibitory balance.

Obviously, dystrophin does not solely play a structural role in central synapses but likely participates to the fine tuning of critical plastic processes through regulation of $\mathrm{GABA}_{\mathrm{A}}-\mathrm{R}$ clusters at inhibitory synapses. Although other classes of receptors may interact with dystrophin (e.g., [135, $137,138]$ ), this "dysfunctional inhibition" hypothesis seems to be supported by studies in $m d x$ mice and may account at least in part for the brain physiological and cognitive alterations associated with DMD [123].

Additionally, putative alterations of the brain vascular permeability have been suggested by some studies, which may also participate to behavioral deficits in $m d x$ mice. Initial observations of $m d x$ brains revealed severe alterations of endothelial cells with open tight junctions surrounded by swollen glial processes, decreased Dp71 and AQP4 expression, and enhanced vascular permeability suggesting BBB breakdown $[139,140]$. Follow-up studies suggested that this results from hypoxic condition leading to the activation of hypoxia inducible factor- $1 \alpha$ contributing to both $\mathrm{BBB}$ opening and compensatory angiogenesis, along with changes in expression of matrix metalloproteinases, nerve and vascular growth factors [141, 142], hence the hypothesis that a progressive decline in respiratory function due to muscle degeneration [143] could worsen the brain and cognitive impairments in advanced DMD patients through a reduction in cerebral oxygenation and $\mathrm{BBB}$ disruption.

7.2. Dp71 Function. The Dp71-null mouse [144] does not have overt muscle pathology or motor impairment and hence constitutes an appropriate model to assess the role of Dp71 in the mammalian brain. Our group recently showed that Dp71-null mice display selective behavioral disturbances characterized by reduced exploratory and novelty-seeking behavior, mild retention deficits in inhibitory avoidance, and impairments in spatial learning and memory, suggesting that dysfunction of this protein may participate to the genesis of mental retardation in DMD [51]. As in other mouse models of inherited mental retardation ([145] for a review), the deficits are correlated with abnormal excitatory synapse organization and function. Dp71-null mice display enhanced glutamatergic transmission and reduced 
synaptic plasticity in the CA1 hippocampal subfield and have a reduced density of excitatory synapses. In Dp71-null cultured neurons, abnormally large clusters of PSD-95 were evidenced, suggesting that altered synaptic function may result from a disorganization of this major signaling protein involved in the clustering of glutamate receptors in the PSDs.

The cellular and molecular bases of these alterations seem complex, since Dp71 has an apparent expression in both glial and neuronal cells. Its subcellular expression and putative binding partners suggest multiple functions. First, Dp71 shows a major expression at the glial-vascular interface, that is, in perivascular astrocyte endfeet $[47,50]$, suggesting a role in BBB function. Mice lacking $\alpha$-syntrophin [146] or Dp71 $[147,148]$ have mistargeted aquaporin (AQP4) waterpermeable channels and altered water homeostasis possibly due to impaired assembly of a specific Dp71-associated complex. Through PDZ-mediated interaction with $\alpha$-syntrophin, the glial DGC also associates with inwardly rectifying $\mathrm{K}^{+}$ channels (e.g., Kir4.1) involved in siphoning $\mathrm{K}^{+}$ions released into the extracellular space after neuronal excitation [149, 150]. It is hypothesized that laminin-dependent aggregation of both Kir4.1 and AQP4 channels is mediated by the Dp71DGC in brain astrocytes [151]. This suggests multiple roles for Dp71 in glia, including regulation of water homeostasis, blood-neural barrier function and $\mathrm{K}^{+}$buffering. Interestingly, a comparable role has been evidenced in Müller glial cell end-feet in the retina, where Dp71 also serves as an anchor for Kir4.1 and AQP4 channels [77]. The Dp71-null retina thus constitutes an original model to assess Dp71 glial function in the CNS, as functional alteration of Müller cells is an early hallmark of most retina diseases. Studies in this model have shown that Dp71 is crucially implicated in the maintenance of potassium and water homeostasis, as well as in the regulation of retinal vascular permeability [152]. Despite a clear dysfunction of blood-retina barrier, no alteration of visual function was observed in the Dp71-null mice [153], suggesting that such Dp71-dependent defects are compensated or do not induce major functional outcomes. The presence of $\mathrm{BBB}$ alterations in the brain of Dp71-null mice remains unclear. The selective loss of Dp71 appears associated with altered BBB osmosensitivity in particular brain structures but defective vascular permeability has not been demonstrated $[148,154]$ and there is no clear evidence that AQP4 depletion could affect this function [155]. However, because astrocytic functions of AQP4 and Kir4.1 channels may contribute to neuronal function and dysfunctional plasticity by regulating the synaptic microenvironment in response to increased neuronal activity, putative contribution of Dp71 to intercellular communication at the neuron-glial and/or glial-vascular interfaces could explain some of the neurological alterations associated with loss-offunction mutations.

Additionally, we showed that a pool of Dp71 colocalizes with key signaling proteins at glutamatergic synapses in cultured neurons, and that Dp71 and DGC members from adult-rodent brain extracts co-immunoprecipitate with several signaling and scaffolding proteins associated with glutamate receptors (NMDAr, AMPAr) in excitatory synapses [51]. This is in agreement with several reports showing Dp71 expression in various neuronal-cell types [49, 156-158] and in adult-brain PSDs [50]. However, as other studies failed to detect DGC components in excitatory synapses in vitro (e.g., [125]), the specific binding partners of the neuronal and/or synaptic pool of Dp71 need to be further specified and putative expression in inhibitory synapses cannot be ruled out.

Dp71 is potentially involved in a variety of brain physiological functions in both glia and neurons, suggesting multifactorial effects of loss-of-function mutations on cognitive functions. Understanding the relevance of each Dp71-dependent process to the physiological and behavioral phenotypes associated with DMD is a major challenge for future research. As the neural basis of mental retardation in DMD results from the combined loss-of-function of all dystrophin gene products, the brain alterations likely encompass glial as well as synaptic dysfunctions involving the GABAergic and glutamatergic systems.

\section{Role of Utrophins in the Mammalian Brain}

Utrophins have not been directly implicated in any known genetic disease. However, they show specific patterns of expression in a variety of tissues and loss-of-function in mice suggest a role in selective cellular functions. As mentioned above, most of our knowledge on utrophin function comes from studies of its role at the neuromuscular synapse. Studies in utrophin-deficient mice revealed a reduction in the number of postsynaptic-membrane folds and acetylcholine receptors at the NMJ. These mice are viable and show no sign of muscular weakness and no compensation by dystrophin expression. Moreover, dystroglycan and dystrobrevin expression remains largely unaffected suggesting that utrophin is dispensable for assembly of the DGC but contributes to proper maturation of the postsynaptic apparatus at the NMJ $[99,100]$. In contrast, mice lacking both dystrophin and utrophin exhibit a severe muscular dystrophy with growth retardation and premature death $[159,160]$. In these mice, $\beta$-dystroglycan is downregulated at the NMJ, whereas dystrobrevin and $\beta 2$-syntrophin are undetectable. Nonetheless, expression of laminin- $\beta 2$, agrin, and rapsyn is unaffected, indicating that postsynaptic differentiation can occur, not only in the absence of both utrophin and dystrophin but also when the DGC is largely disrupted.

Much less is known about the function of utrophingene products in brain. Expression in choroids plexus and brain vasculature suggests a role in the proper functioning of the BBB. Utrophin-deficient (Utrn-/-) mice have decreased expression of the associated UGC components in epithelial cells of choroids plexus and endothelial cells of microvasculature, indicating that utrophin is required for proper assembly of the brain UGC [47]. However, no gross morphological changes were observed in these structures in Utrn-/- mice and the role of UGC is still unclear.

A possible role for utrophin in a subset of neurons remains to be investigated. The pattern of utrophin expression around the soma of neurons is at variance with the punctate expression of dystrophin in synaptic structures, 
suggesting that utrophin provides structural support for neuronal membranes, whereas dystrophin is a component of inhibitory synapses. Interestingly, very strong utrophin immunoreactivity was reported several weeks after induction of morphogenic changes in granule cells of the dentate gyrus in an experimental model of temporal lobe epilepsy, which suggested that utrophin contributes to protect CNS neurons against pathological insults via long-term structural stabilization of their membranes [161].

The localization and functional characterization of the short C-terminal forms of utrophin is still at its infancy, although several studies suggested their participation in compensatory mechanisms in dystrophin-deficient tissues $[78,162,163]$ (see next section).

\section{Therapies for DMD: From Muscle to Brain}

The last decades of research on therapeutics for DMD yielded a range of options to alleviate muscular dystrophy and/or partly correct the cellular alterations resulting from congenital loss of dystrophin. From pharmacological intervention to gene therapy, several approaches might be translated to brain, with the hope to progress toward treatments that could alleviate both the muscular and cognitive alterations in DMD.

Numerous pharmacological treatments have been considered to ameliorate the dystrophic-muscle phenotype in DMD. Some of them enabled partial compensation of specific physiological alterations. For example, blockade of calcium channel and inhibition of calpain-dependent processes were used to maintain calcium homeostasis, whereas inhibition of myostatin or administration of insulinlike growth factor provided significant increases in muscle strength and mass (reviewed in [164]). Steroid therapy involving administration of Deflazacort or Prednisolone has long been shown to be beneficial and is currently applied to the patients to reduce inflammation. Such treatments are however mostly supportive, associated with side effects $[165,166]$, and do not provide means to correct the causes of DMD. Also, specific treatments should be developed to alleviate the cognitive deficits in DMD and could be used in combination with muscle medical management. Pharmacological strategies could involve modulation of the GABAergic function, shown to be altered in the brain of $m d x$ mice. Below we discuss recent advances made in the search of efficient therapeutics for DMD and their applicability to brain therapies.

9.1. Muscle Stem and Progenitor Cell Therapies. Cellular therapies to alleviate muscle degeneration can be divided into two strategies. First, normal precursor cells (satellite cells) can be introduced into dystrophic muscle to differentiate into new myofibers, leading to a relocalization of dystrophin at the muscle sarcolemma, as shown in $m d x$ mice [167]. However, this technique shows limited intramuscular migration and triggers immune responses against introduced cells or against the dystrophin itself. These obstacles can be partly overcome by immunosuppression, multiple injections with high-titration cell suspensions, and different other technologies that improve myoblast transfer. This, however, remains a harsh intervention that only permits restoration of about $30 \%$ of dystrophin-positive fibers (reviewed in [168]). A second strategy relies on transplantation of bone marrow or specific stem cells. Although this has a good potential to regenerate dystrophic muscle [168, 169], it also comes along with immunogenicity and generally hampers combination with other treatments. Moreover, cell therapies placed a focus on muscle treatment and do not find immediate application to the brain alterations in DMD.

9.2. Exogenous Dystrophin Delivery. Regulated gene transfer for ectopic expression of dystrophin cDNA has met with little success and faces many obstacles including limited vector delivery, construction instability, immunogenicity, and poor control of protein expression levels. The large size of the DMD gene, which cannot be cloned in viral vectors, hindered the possibility to deliver a complete form of dystrophin. Most experimental success has been achieved using truncated dystrophin minigenes that give rise to mini-dystrophin lacking part of the central rod domain. Although this approach brought some hope to convert a DMD phenotype into that of the milder BMD $[170,171]$, progress is needed to achieve systemic administration to treat all affected tissues including the brain.

9.3. Modulation of Utrophins Expression. Full-length utrophin has a high level of expression in foetal and regenerating muscles. Interestingly, muscle necrosis in $m d x$ mice occurs only when utrophin expression level falls down to adult level, that is, at the time it should be replaced by dystrophin [67]. Hence, it has long been considered that utrophin and dystrophin subserve comparable functions during foetal development and adulthood, and that maintaining utrophin expression in adult dystrophic tissues could compensate for dystrophin loss. In support of this hypothesis, utrophin expression is spontaneously regulated in mouse models of DMD, suggesting endogenous compensations. In $m d x$ skeletal muscles, Utrn-A is overexpressed and extends along the sarcolemma, whereas Utrn-B expression is increased in vascular elements [78]. In $m d x$ cardiac muscles, Utrn-A is also overexpressed [68], while in $m d x$ diaphragm, the short utrophin isoform Up71 and $\beta$-dystroglycan are upregulated and accumulate in regenerating areas [163]. Spontaneous upregulations also occur in nonmuscle tissues, such as in Dp71-deficient platelets [172], and most importantly in brains of DMD mouse models [78, 112, 162]. Although the upregulation of brain utrophins is a matter of debate [39], a recent report shows that full-length utrophins are overexpressed in the brain of Dp427-deficient $m d x$ mice; yet their expression in distinct structures as compared to dystrophin may not help functional compensation [78]. Interestingly, overexpression of Up71 and Up113, but not of full-length utrophin, has been reported in the brain $m d x^{3 C V}$ mice lacking all dystrophin-gene products [162]. However in these mice, the severe alteration of the Dp71-DGC 
in glial endfeet is not compensated [47]. Taken together the data suggest that utrophins are involved in tenuous compensatory processes but cannot fully replace dystrophin function. While utrophin upregulation in muscles may participate to the slow progression of myopathy in the $m d x$ model, a better understanding of the complex interplay between dystrophins and utrophins is needed to define specific targets for pharmacological approaches in the brain.

The potential of exogenous utrophin has been demonstrated using transgene and viral vector administration [170, $173,174]$. Delivery of a microutrophin in $m d x$ (Utrn-/-) mice has been recently achieved through intravenous administration of a recombinant adeno-associated virus (rAAV). This restored expression of the muscle DGC and improved animals' dystrophic phenotype [175]. The strategy however faces similar difficulties as with dystrophin-gene transfer. Therefore, alternative ways are currently being considered to regulate endogenous utrophins rather than promoting ectopic expression.

Several pharmacological strategies have been employed in an attempt to regulate endogenous utrophins. First, administration of L-Arginine, the substrate of NO synthase (NOS), or that of NO donors like molsidomine has been shown to upregulate utrophin in muscle fibers in $m d x$ mice, to restructure their muscle phenotype, and to reduce necrosis and contraction-induced damages [176-178]. L-arginine likely induces other beneficial effects in $m d x$ muscles, such as reversion of lipid patterns in muscle membrane, reduction of inflammatory signals, decreased activity of matrix metalloproteinase (MMP), and downregulation of NFkappaB, which may or may not depend on utrophin regulation [179-181]. There is no direct evidence that NO ameliorates the $m d x$ phenotype through upregulation of utrophin. However, owing to the multiple actions of NO and because NOS associates with the DGC in both muscle and nonmuscle tissues, the potential of NOS modulation to improve brain alterations in DMD should be considered. In this vein, a recent study shows that upregulating nNOS in muscles compensates altered neurogenesis in $m d x$ mice hippocampus [182], suggesting that some brain alterations in this model might be secondary to the myopathy and/or to associated metabolic dysfunctions.

Alternatively, utrophin's promoter activity can be modulated by specific transcription factors, growth factors, or activators of upstream pathways. The postsynaptic expression of Utrn-A is regulated by heregulin, a nerve-derived signalling molecule of the neuregulin family, which acts on the N-box motif of utrophin promoter via the GA-binding proteins, GABP $\alpha$ and $\mathrm{GABP} \beta$ [183]. This can upregulate utrn-A and improve the $m d x$ phenotype [184]. Heregulin can pass through BBB and potentially act in the CNS [185]. Regulation by a calcineurin-dependent activation of the Nuclear Factor of Activated T-cell (NFAT) also improves the dystrophic phenotype [186-188]. Posttranscriptional mechanisms [189] and their regulations by certain transcription factors, such as the peroxysome proliferator-activated receptor $(\operatorname{PPAR} \beta / \delta)$ [190], have been recently uncovered and may provide new scent towards therapeutic approaches involving regulation of utrophin promoters.
9.4. Suppressing Mutations to Restore Dystrophin Expression. While systemic administration is a main advantage of pharmacological approaches, the risk for nonspecific actions and side effects remains a major drawback. The development of new molecular tools allowed a change in the focus of therapeutic strategies towards the correction of gene anomalies to rescue the missing protein (reviewed in [191]). Approximately $5 \%-15 \%$ of DMD cases are caused by nonsense mutation in the dystrophin gene. A way to efficiently rescue dystrophin expression uses aminoglycoside antibiotics like gentamycin, which interfere with the ribosome ability to recognize premature-termination codons (PTC) and thus restore open reading frame $[192,193]$. This however results in long-term toxicity with few good-responder patients [194]. New nonsense-codon suppressor molecules are being developed [195], such as the non-aminoglygoside PTCreadthrough compounds (e.g., PTC124) currently under clinical trial in DMD boys $[196,197]$. Putative applications in brain therapy have not been explored and may depend on molecules capacity to cross the $\mathrm{BBB}$ and long-term side effects.

Another approach arose from the observation that spontaneous exon skipping may lead to the presence of dystrophin-positive fibers in dystrophic muscles. Hence, synthetic antisense oligonucleotides (AONs) have been recently used to redirect splicing of the dystrophin pre-mRNA and induce skipping of the mutated exon 23 that contains the stop codon in $m d x$ mice, thus generating a truncated transcript with restored open reading frame [191, 198]. In theory, exon skipping and production of truncated dystrophins would be applicable to a large subgroup of DMD patients as far as truncation does not affect critical C-terminal domains, but the functionality of different in-frame dystrophins needs to be determined in future researches [198]. One most often mutated exon in DMD is exon 51; a strategy based on skipping of this exon is currently under trial using two target molecules, 2-O-methyl-AON or PR0051 [199] and morpholino AVI-4658 [200]. Intramuscular injection of AONs safely enables reexpression of dystrophin. However, high and repeated doses are required for lasting expression of dystrophin due to limited uptake through passive diffusion. Several methods have been explored to enhance efficiency of AONs delivery, including use of different carriers (nanopolymers, nanospheres) and conjugation to short arginine-rich cell-penetrating peptides (CPPs) to increase cellular uptake [201]. The capacity of AONs to pass through the BBB is null. However, dystrophin rescue could be achieved in brain of $m d x$ mice by intracerebroventricular morpholino injections, which resulted in beneficial behavioural effects [40]. To circumvent problems related to the stability and uptake of AONs, they can be linked to a modified U7 small nuclear RNA (snRNA) sequence, which is naturally implicated in the splicing of histone-transcript and therefore enables correct subcellular localization. This construct, when expressed in rAAV vectors, can drive long-term dystrophin expression with low immunogenicity, good cellular tropism, and transduction efficiency in various muscle and nonmuscle tissues. In $m d x$ mice, intramuscular injection of a single dose of rAAV2/1-U7 system is efficient to skip exon 23, drive 
sustained therapeutic levels of rescued dystrophin, and correct muscular dystrophy [202]. This approach has recently been further developed with the addition of binding sites for heterogeneous ribonucleoprotein $\mathrm{A} 1$, to improve nuclear targeting of mRNAs [203]. Specific rAAV serotypes also display good neuronal tropism and transduction efficiency in rodent brain tissue in vivo [204,205], suggesting that they may also be used to alleviate the brain alterations in DMD.

\section{Conclusion}

Viewed as a structural protein ensuring muscle membrane stability in the 1980s, dystrophin is now considered as the central component of a scaffold of proteins expressed in a variety of tissues including the brain, where it is involved in the clustering of several membrane receptors and ion channels and in the modulation of cellular signal integration and synaptic plasticity. The last two decades of research on DMD enabled major breakthrough into new and critical cellular processes, such as the clustering of $\mathrm{GABA}_{\mathrm{A}} \mathrm{R}$ at central inhibitory synapses and the organization of the molecular machinery involved in water and $\mathrm{K}^{+}$homeostasis at the glial-vascular interface. Despite major advances, the specific contribution of each of the dystrophins to the genesis of cognitive impairment in DMD needs further specifications. Research on brain utrophins is still at its infancy, but it may also favor the discovery of new mechanisms and contribute to significant progress in the search of efficient therapeutics for DMD. The rapid development of modern pharmacological and molecular tools to modulate expression of the utrophin/dystrophin family of proteins brings hope for the future design of appropriate therapies that will treat both the muscle and brain impairments associated with DMD.

\section{Acknowledgments}

The first author was a recipient of a fellowship from the Ministère de l'Enseignement Supérieur et de la Recherche (France). The authors thank the A.F.M. (Association Française contre les Myopathies, France), CNRS, and University of Paris Sud for supporting this research, and Serge Laroche for his comments on the manuscript.

\section{References}

[1] E. P. Hoffman, R. H. Brown Jr., and L. M. Kunkel, "Dystrophin: the protein product of the Duchenne muscular dystrophy locus," Cell, vol. 51, no. 6, pp. 919-928, 1987.

[2] V. J. Hinton, B. C. De Vivo, N. E. Nereo, E. Goldstein, and Y. Stern, "Poor verbal working memory across intellectual level in boys with Duchenne dystrophy," Neurology, vol. 54, no. 11, pp. 2127-2132, 2000.

[3] I. Desguerre, C. Christov, M. Mayer, et al., "Clinical heterogeneity of Duchenne muscular dystrophy (DMD): definition of sub-phenotypes and predictive criteria by long-term follow-up," PloS One, vol. 4, no. 2, article e4347, 2009.

[4] D. J. Blake, A. Weir, S. E. Newey, and K. E. Davies, "Function and genetics of dystrophin and dystrophin-related proteins in muscle," Physiological Reviews, vol. 82, no. 2, pp. 291-329, 2002.
[5] T. Haenggi and J.-M. Fritschy, "Role of dystrophin and utrophin for assembly and function of the dystrophin glycoprotein complex in non-muscle tissue," Cellular and Molecular Life Sciences, vol. 63, no. 14, pp. 1614-1631, 2006.

[6] G. S. K. Pilgram, S. Potikanond, R. A. Baines, L. G. Fradkin, and J. N. Noordermeer, "The roles of the dystrophinassociated glycoprotein complex at the synapse," Molecular Neurobiology, vol. 41, no. 1, pp. 1-21, 2010.

[7] C. Billard, P. Gillet, J. L. Signoret, et al., "Cognitive functions in duchenne muscular dystrophy: a reappraisal and comparison with spinal muscular atrophy," Neuromuscular Disorders, vol. 2, no. 5-6, pp. 371-378, 1992.

[8] S. Cotton, N. J. Voudouris, and K. M. Greenwood, "Intelligence and Duchenne muscular dystrophy: full-scale, verbal, and performance intelligence quotients," Developmental Medicine and Child Neurology, vol. 43, no. 7, pp. 497-501, 2001.

[9] C. Billard, P. Gillet, M.-A. Barthez, C. Hommet, and P. Bertrand, "Reading ability and processing in Duchenne muscular dystrophy and spinal muscular atrophy," Developmental Medicine and Child Neurology, vol. 40, no. 1, pp. 12-20, 1998.

[10] M. Roccella, R. Pace, and M. T. De Gregorio, "Psychopathological assessment in children affected by Duchenne de Boulogne muscular dystrophy," Minerva Pediatrica, vol. 55, no. 3, pp. 267-276, 2003.

[11] V. J. Hinton, D. C. De Vivo, N. E. Nereo, E. Goldstein, and Y. Stern, "Selective deficits in verbal working memory associated with a known genetic etiology: the neuropsychological profile of Duchenne muscular dystrophy," Journal of the International Neuropsychological Society, vol. 7, no. 1, pp. 45-54, 2001.

[12] J. G. M. Hendriksen and J. S. H. Vles, "Neuropsychiatric disorders in males with duchenne muscular dystrophy: frequency rate of attention-deficit hyperactivity disorder (ADHD), autism spectrum disorder, and obsessivecompulsive disorder," Journal of Child Neurology, vol. 23, no. 5, pp. 477-481, 2008.

[13] V. J. Hinton, N. E. Nereo, R. J. Fee, and S. E. Cyrulnik, "Social behavior problems in boys with Duchenne muscular dystrophy," Journal of Developmental and Behavioral Pediatrics, vol. 27, no. 6, pp. 470-476, 2006.

[14] V. J. Hinton, R. J. Fee, D. C. De Vivo, and E. Goldstein, "Poor facial affect recognition among boys with Duchenne muscular dystrophy," Journal of Autism and Developmental Disorders, vol. 37, no. 10, pp. 1925-1933, 2007.

[15] J. Donders and C. Taneja, "Neurobehavioral characteristics of children with duchenne muscular dystrophy," Child Neuropsychology, vol. 15, no. 3, pp. 295-304, 2009.

[16] S. E. Cyrulnik and V. J. Hinton, "Duchenne muscular dystrophy: a cerebellar disorder?" Neuroscience and Biobehavioral Reviews, vol. 32, no. 3, pp. 486-496, 2008.

[17] H. G. W. Lidov, T. J. Byers, and L. M. Kunkel, "The distribution of dystrophin in the murine central nervous system: an immunocytochemical study," Neuroscience, vol. 54, no. 1, pp. 167-187, 1993.

[18] D. Rapaport, M. R. Passos-Bueno, L. Brandao, D. Love, M. Vainzof, and M. Zatz, "Apparent association of mental retardation and specific patterns of deletions screened with probes cf56a and cf23a in Duchenne Muscular Dystrophy," American Journal of Medical Genetics, vol. 39, no. 4, pp. 437441, 1991. 
[19] U. Lenk, R. Hanke, H. Thiele, and A. Speer, "Point mutations at the carboxy terminus of the human dystrophin gene: implications for an association with mental retardation in DMD patients," Human Molecular Genetics, vol. 2, no. 11, pp. 1877-1881, 1993.

[20] M.-P. Moizard, C. Billard, A. Toutain, F. Berret, N. Marmin, and C. Moraine, "Are Dp71 and Dp140 brain dystrophin isoforms related to cognitive impairment in Duchenne muscular dystrophy?" American Journal of Medical Genetics, vol. 80, no. 1, pp. 32-41, 1998.

[21] M.-P. Moizard, A. Toutain, D. Fournier, et al., "Severe cognitive impairment in DMD: obvious clinical indication for Dp71 isoform point mutation screening," European Journal of Human Genetics, vol. 8, no. 7, pp. 552-556, 2000.

[22] G. Felisari, F. M. Boneschi, A. Bardoni, et al., "Loss of Dp140 dystrophin isoform and intellectual impairment in Duchenne dystrophy," Neurology, vol. 55, no. 4, pp. 559-564, 2000.

[23] F. Daoud, N. Angeard, B. Demerre, et al., "Analysis of Dp71 contribution in the severity of mental retardation through comparison of Duchenne and Becker patients differing by mutation consequences on Dp71 expression," Human Molecular Genetics, vol. 18, no. 20, pp. 3779-3794, 2009.

[24] P. J. Taylor, G. A. Betts, S. Maroulis, et al., "Dystrophin gene mutation location and the risk of cognitive impairment in duchenne muscular dystrophy," PloS One, vol. 5, no. 1, article e8803, 2010.

[25] F. Muntoni, S. Torelli, and A. Ferlini, "Dystrophin and mutations: one gene, several proteins, multiple phenotypes," Lancet Neurology, vol. 2, no. 12, pp. 731-740, 2003.

[26] L. V. B. Nicholson, M. A. Johnson, K. M. D. Bushby, et al., "Integrated study of 100 patients with Xp21 linked muscular dystrophy using clinical, genetic, immunochemical, and histopathological data. Part 1. Trends across the clinical groups," Journal of Medical Genetics, vol. 30, no. 9, pp. 728736, 1993.

[27] J. A. Rafael, G. A. Cox, K. Corrado, D. Jung, K. P. Campbell, and J. S. Chamberlain, "Forced expression of dystrophin deletion constructs reveals structure-function correlations," Journal of Cell Biology, vol. 134, no. 1, pp. 93-102, 1996.

[28] H. M. Sadoulet-Puccio and L. M. Kunkel, "Dystrophin and its isoforms," Brain Pathology, vol. 6, no. 1, pp. 25-35, 1996.

[29] S. J. Winder, "The membrane-cytoskeleton interface: the role of dystrophin and utrophin," Journal of Muscle Research and Cell Motility, vol. 18, no. 6, pp. 617-629, 1997.

[30] T. S. Khurana and K. E. Davies, "Pharmacological strategies for muscular dystrophy," Nature Reviews Drug Discovery, vol. 2, no. 5, pp. 379-390, 2003.

[31] M. Luise, C. Presotto, L. Senter, et al., "Dystrophin is phosphorylated by endogenous protein kinases," Biochemical Journal, vol. 293, no. 1, pp. 243-247, 1993.

[32] H. W. Jarrett and J. L. Foster, "Alternate binding of actin and calmodulin to multiple sites on dystrophin," Journal of Biological Chemistry, vol. 270, no. 10, pp. 5578-5586, 1995.

[33] L. Senter, S. Ceoldo, M. M. Petrusa, and G. Salviati, "Phosphorylation of dystrophin: effects on actin binding," Biochemical and Biophysical Research Communications, vol. 206, no. 1, pp. 57-63, 1995.

[34] M. Michalak, S. Y. Fu, R. E. Milner, J. L. Busaan, and J. E. Hance, "Phosphorylation of the carboxyl-terminal region of dystrophin," Biochemistry and Cell Biology, vol. 74, no. 4, pp. 431-437, 1996.
[35] M. P. Walsh, J. L. Busaan, E. D. Fraser, S. Y. Fu, M. D. Pato, and M. Michalak, "Characterization of the recombinant C-terminal domain of dystrophin: phosphorylation by calmodulin-dependent protein kinase II and dephosphorylation by type 2B protein phosphatase," Biochemistry, vol. 34, no. 16, pp. 5561-5568, 1995.

[36] T. A. Rando, “The dystrophin-glycoprotein complex, cellular signaling, and the regulation of cell survival in the muscular dystrophies," Muscle and Nerve, vol. 24, no. 12, pp. 15751594, 2001.

[37] C. G. Carlson, "The dystrophinopathies: an alternative to the structural hypothesis," Neurobiology of Disease, vol. 5, no. 1, pp. 3-15, 1998.

[38] H. G. W. Lidov, "Dystrophin in the nervous system," Brain Pathology, vol. 6, no. 1, pp. 63-77, 1996.

[39] I. Knuesel, B. C. Bornhauser, R. A. Zuellig, F. Heller, M. C. Schaub, and J.-M. Fritschy, "Differential expression of utrophin and dystrophin in CNS neurons: an in situ hybridization and immunohistochemical study," Journal of Comparative Neurology, vol. 422, no. 4, pp. 594-611, 2000.

[40] M. Sekiguchi, K. Zushida, M. Yoshida, et al., "A deficit of brain dystrophin impairs specific amygdala GABAergic transmission and enhances defensive behaviour in mice," Brain, vol. 132, no. 1, pp. 124-135, 2009.

[41] D.-A. M. Pillers, R. G. Weleber, D. G. Green, et al., "Effects of dystrophin isoforms on signal transduction through neural retina: genotype-phenotype analysis of Duchenne muscular dystrophy mouse mutants," Molecular Genetics and Metabolism, vol. 66, no. 2, pp. 100-110, 1999.

[42] M. F. Costa, A. G. F. Oliveira, C. Feitosa-Santana, M. Zatz, and D. F. Ventura, "Red-green color vision impairment in Duchenne muscular dystrophy," American Journal of Human Genetics, vol. 80, no. 6, pp. 1064-1075, 2007.

[43] G. E. Morris, C. Simmons, and N. T. Man, "Apo-dystrophins (DP140 and DP71) and dystrophin splicing isoforms in developing brain," Biochemical and Biophysical Research Communications, vol. 215, no. 1, pp. 361-367, 1995.

[44] H. G. W. Lidov, S. Selig, and L. M. Kunkel, "Dp140: a novel 140 kDa CNS transcript from the dystrophin locus," Human Molecular Genetics, vol. 4, no. 3, pp. 329-335, 1995.

[45] T. J. Byers, H. G. W. Lidov, and L. M. Kunkel, "An alternative dystrophin transcript specific to peripheral nerve," Nature Genetics, vol. 4, no. 1, pp. 77-81, 1993.

[46] T.-W. Kim, K. Wu, J.-L. Xu, and I. B. Black, "Detection of dystrophin in the postsynaptic density of rat brain and deficiency in a mouse model of Duchenne muscular dystrophy," Proceedings of the National Academy of Sciences of the United States of America, vol. 89, no. 23, pp. 11642-11644, 1992.

[47] T. Haenggi, A. Soontornmalai, M. C. Schaub, and J.-M. Fritschy, "The role of utrophin and Dp71 for assembly of different dystrophin-associated protein complexes (DPCs) in the choroid plexus and microvasculature of the brain," Neuroscience, vol. 129, no. 2, pp. 403-413, 2004.

[48] D. C. Gorecki and E. A. Barnard, "Specific expression of Gdystrophin (Dp71) in the brain," NeuroReport, vol. 6, no. 6, pp. 893-896, 1995.

[49] V. Aleman, B. Osorio, O. Chavez, A. Rendon, D. Mornet, and D. Martinez, "Subcellular localization of Dp71 dystrophin isoforms in cultured hippocampal neurons and forebrain astrocytes," Histochemistry and Cell Biology, vol. 115, no. 3, pp. 243-254, 2001. 
[50] D. J. Blake, R. Hawkes, M. A. Benson, and P. W. Beesley, "Different dystrophin-like complexes are expressed in neurons and glia," Journal of Cell Biology, vol. 147, no. 3, pp. 645-658, 1999.

[51] F. Daoud, A. Candelario-Martinez, J. M. Billard, et al., "Role of mental retardation-associated dystrophin-gene product Dp71 in excitatory synapse organization, synaptic plasticity and behavioral functions," PloS One, vol. 4, no. 8, p. e6574, 2009.

[52] C. N. Tennyson, H. J. Klamut, and R. G. Worton, "The human dystrophin gene requires 16 hours to be transcribed and is cotranscriptionally spliced," Nature Genetics, vol. 9, no. 2, pp. 184-190, 1995.

[53] R. C. Austin, P. L. Howard, V. N. D’Souza, H. J. Klamut, and P. N. Ray, "Cloning and characterization of alternatively spliced isoforms of Dp71," Human Molecular Genetics, vol. 4, no. 9, pp. 1475-1483, 1995.

[54] H. G. W. Lidov and L. M. Kunkel, "Dp140: alternatively spliced isoforms in brain and kidney," Genomics, vol. 45, no. 1, pp. 132-139, 1997.

[55] F. G. Marquez, B. Cisneros, F. Garcia, et al., "Differential expression and subcellular distribution of dystrophin Dp71 isoforms during differentiation process," Neuroscience, vol. 118, no. 4, pp. 957-966, 2003.

[56] R. C. Austin, G. E. Morris, P. L. Howard, H. J. Klamut, and P. N. Ray, "Expression and synthesis of alternatively spliced variants of Dp71 in adult human brain," Neuromuscular Disorders, vol. 10, no. 3, pp. 187-193, 2000.

[57] R. C. Austin, J. E. B. Fox, G. H. Werstuck, et al., "Identification of Dp71 isoforms in the platelet membrane cytoskeleton: potential role in thrombin-mediated platelet adhesion," Journal of Biological Chemistry, vol. 277, no. 49, pp. 4710647113, 2002.

[58] M. Ceccarini, G. Rizzo, G. Rosa, C. Chelucci, P. Macioce, and T. C. Petrucci, "A splice variant of Dp71 lacking the syntrophin binding site is expressed in early stages of human neural development," Developmental Brain Research, vol. 103, no. 1, pp. 77-82, 1997.

[59] H. Jin, S. Tan, J. Hermanowski, et al., "The dystrotelin, dystrophin and dystrobrevin superfamily: new paralogues and old isoforms," BMC Genomics, vol. 8, article 19, 2007.

[60] D. R. Love, D. F. Hill, G. Dickson, et al., "An autosomal transcript in skeletal muscle with homology to dystrophin," Nature, vol. 339, no. 6219, pp. 55-58, 1989.

[61] J. M. Tinsley, D. J. Blake, A. Roche, et al., "Primary structure of dystrophin-related protein," Nature, vol. 360, no. 6404, pp. 591-593, 1992.

[62] V. J. Buckle, J. L. Guenet, D. Simon-Chazottes, D. R. Love, and K. E. Davies, "Localisation of a dystrophin-related autosomal gene to $6 \mathrm{q} 24$ in man, and to mouse chromosome 10 in the region of the dystrophia muscularis (dy) locus," Human Genetics, vol. 85, no. 3, pp. 324-326, 1990.

[63] E. Prochniewicz, D. Henderson, J. M. Ervasti, and D. D. Thomas, "Dystrophin and utrophin have distinct effects on the structural dynamics of actin," Proceedings of the National Academy of Sciences of the United States of America, vol. 106, no. 19, pp. 7822-7827, 2009.

[64] S. J. Winder, T. J. Gibson, and J. Kendrick-Jones, "Dystrophin and utrophin: the missing links!," FEBS Letters, vol. 369, no. 1, pp. 27-33, 1995.

[65] C. L. Dennis, J. M. Tinsley, A. E. Deconinck, and K. E. Davies, "Molecular and functional analysis of the utrophin promoter," Nucleic Acids Research, vol. 24, no. 9, pp. 1646$1652,1996$.
[66] E. A. Burton, J. M. Tinsley, P. J. Holzfeind, N. R. Rodrigues, and K. E. Davies, "A second promoter provides an alternative target for therapeutic up-regulation of utrophin in Duchenne muscular dystrophy," Proceedings of the National Academy of Sciences of the United States of America, vol. 96, no. 24, pp. 14025-14030, 1999.

[67] T. S. Khurana, S. C. Watkins, P. Chafey, et al., "Immunolocalization and developmental expression of dystrophin related protein in skeletal muscle," Neuromuscular Disorders, vol. 1, no. 3, pp. 185-194, 1991.

[68] A. P. Weir, E. A. Burton, G. Harrod, and K. E. Davies, "A- and B-utrophin have different expression patterns and are differentially up-regulated in mdx muscle," Journal of Biological Chemistry, vol. 277, no. 47, pp. 45285-45290, 2002.

[69] J. M. Tinsley and K. E. Davies, "Utrophin: a potential replacement for dystrophin?” Neuromuscular Disorders, vol. 3, no. 5-6, pp. 537-539, 1993.

[70] K. Ohlendieck, J. M. Ervasti, K. Matsumura, S. D. Kahl, C. J. Leveille, and K. P. Campbell, "Dystrophin-related protein is localized to neuromuscular junctions of adult skeletal muscle," Neuron, vol. 7, no. 3, pp. 499-508, 1991.

[71] F. Rivier, A. Robert, G. Hugon, and D. Mornet, "Different utrophin and dystrophin properties related to their vascular smooth muscle distributions," FEBS Letters, vol. 408, no. 1, pp. 94-98, 1997.

[72] J. P. Earnest, G. F. Santos, S. Zuerbig, and J. E. B. Fox, "Dystrophin-related protein in the platelet membrane skeleton. Integrin- induced change in detergent-insolubility and cleavage by calpain in aggregating platelets," Journal of Biological Chemistry, vol. 270, no. 45, pp. 27259-27265, 1995.

[73] C. N. Lumeng, S. F. Phelps, J. A. Rafael, et al., "Characterization of dystrophin and utrophin diversity in the mouse," Human Molecular Genetics, vol. 8, no. 4, pp. 593-599, 1999.

[74] K. Matsumura, H. Yamada, T. Shimizu, and K. P. Campbell, "Differential expression of dystrophin, utrophin and dystrophin-associated proteins in peripheral nerve," FEBS Letters, vol. 334, no. 3, pp. 281-285, 1993.

[75] T. S. Khurana, S. C. Watkins, and L. M. Kunkel, "The subcellular distribution of chromosome 6-encoded dystrophinrelated protein in the brain," Journal of Cell Biology, vol. 119, no. 2, pp. 357-366, 1992.

[76] K. Kamakura, Y. Tadano, M. Kawai, et al., "Dystrophinrelated protein is found in the central nervous system of mice at various developmental stages, especially at the postsynaptic membrane," Journal of Neuroscience Research, vol. 37, no. 6, pp. 728-734, 1994.

[77] P. E. Fort, A. Sene, T. Pannicke, et al., "Kir4.1 and AQP4 associate with Dp71- and utrophin-DAPs complexes in specific and defined microdomains of Muller retinal glial cell membrane," Glia, vol. 56, no. 6, pp. 597-610, 2008.

[78] S. M. Baby, S. Bogdanovich, G. Willmann, U. Basu, O. Lozynska, and T. S. Khurana, "Differential expression of utrophin-A and -B promoters in the central nervous system (CNS) of normal and dystrophic mdx mice," Brain Pathology, vol. 20, no. 2, pp. 323-342, 2010.

[79] D. J. Blake, J. N. Schofield, R. A. Zuellig, et al., "G-utrophin, the autosomal homologue of dystrophin Dp116, is expressed in sensory ganglia and brain," Proceedings of the National Academy of Sciences of the United States of America, vol. 92, no. 9, pp. 3697-3701, 1995.

[80] J. Wilson, W. Putt, C. Jimenez, and Y. H. Edwards, "Up71 and Up140, two novel transcripts of utrophin that are homologues of short forms of dystrophin," Human Molecular Genetics, vol. 8, no. 7, pp. 1271-1278, 1999. 
[81] E. Fabbrizio, J. Latouche, F. Rivier, G. Hugon, and D. Mornet, "Re-evaluation of the distributions of dystrophin and utrophin in sciatic nerve," Biochemical Journal, vol. 312, no. 1, pp. 309-314, 1995.

[82] R. A. Zuellig, B. C. Bornhauser, I. Knuesel, F. Heller, J.-M. Fritschy, and M. C. Schaub, "Identification and characterisation of transcript and protein of a new short N-terminal utrophin isoform," Journal of Cellular Biochemistry, vol. 77, no. 3, pp. 418-431, 2000.

[83] C. Jimenez-Mallebrera, K. Davies, W. Putt, and Y. H. Edwards, "A study of short utrophin isoforms in mice deficient for full-length utrophin," Mammalian Genome, vol. 14 , no. 1, pp. 47-60, 2003.

[84] R. G. Roberts, T. C. Freeman, E. Kendall, et al., "Characterization of DRP2, a novel human dystrophin homologue," Nature Genetics, vol. 13, no. 2, pp. 223-226, 1996.

[85] R. G. Roberts and M. Sheng, "Association of dystrophinrelated protein 2 (DRP2) with postsynaptic densities in rat brain," Molecular and Cellular Neuroscience, vol. 16, no. 5, pp. 674-685, 2000.

[86] D. L. Sherman, C. Fabrizi, C. Stewart Gillespie, and P. J. Brophy, "Specific disruption of a Schwann cell dystrophinrelated protein complex in a demyelinating neuropathy," Neuron, vol. 30, no. 3, pp. 677-687, 2001.

[87] D. J. Blake, R. Nawrotzki, M. F. Peters, S. C. Froehner, and K. E. Davies, "Isoform diversity of dystrobrevin, the murine 87$\mathrm{kDa}$ postsynaptic protein," Journal of Biological Chemistry, vol. 271, no. 13, pp. 7802-7810, 1996.

[88] K. Ohlendieck, "Characterisation of the dystrophin-related protein utrophin in highly purified skeletal muscle sarcolemma vesicles," Biochimica et Biophysica Acta, vol. 1283, no. 2, pp. 215-222, 1996.

[89] D. E. Albrecht and S. C. Froehner, "Syntrophins and dystrobrevins: defining the dystrophin scaffold at synapses," NeuroSignals, vol. 11, no. 3, pp. 123-129, 2002.

[90] A. Waite, C. L. Tinsley, M. Locke, and D. J. Blake, "The neurobiology of the dystrophin-associated glycoprotein complex," Annals of Medicine, vol. 41, no. 5, pp. 344-359, 2009.

[91] R. A. Williamson, M. D. Henry, K. J. Daniels, et al., "Dystroglycan is essential for early embryonic development: disruption of Reichert's membrane in Dag1-null mice," Human Molecular Genetics, vol. 6, no. 6, pp. 831-841, 1997.

[92] S. A. Moore, F. Saito, J. Chen, et al., "Deletion of brain dystroglycan recapitulates aspects of congenital muscular dystrophy," Nature, vol. 418, no. 6896, pp. 422-425, 2002.

[93] F. Muntoni, M. Brockington, S. Torelli, and S. C. Brown, "Defective glycosylation in congenital muscular dystrophies," Current Opinion in Neurology, vol. 17, no. 2, pp. 205-209, 2004.

[94] D. J. Glass and G. D. Yancopoulos, "Sequential roles of agrin, MuSK and rapsyn during neuromuscular junction formation," Current Opinion in Neurobiology, vol. 7, no. 3, pp. 379-384, 1997.

[95] M. Cavaldesi, G. Macchia, S. Barca, P. Defilippi, G. Tarone, and T. C. Petrucci, "Association of the dystroglycan complex isolated from bovine brain synaptosomes with proteins involved in signal transduction," Journal of Neurochemistry, vol. 72, no. 4, pp. 1648-1655, 1999.

[96] M. A. Benson, S. E. Newey, E. Martin-Rendon, R. Hawkes, and D. J. Blake, "Dysbindin, a a novel coiled-coil-containing protein that interacts with the dystrobrevins in muscle and brain," Journal of Biological Chemistry, vol. 276, no. 26, pp. 24232-24241, 2001.
[97] K. Talbot, D.-S. Cho, W.-Y. Ong, et al., "Dysbindin-1 is a synaptic and microtubular protein that binds brain snapin," Human Molecular Genetics, vol. 15, no. 20, pp. 3041-3054, 2006.

[98] S. Taneichi-Kuroda, S. Taya, T. Hikita, Y. Fujino, and K. Kaibuchi, "Direct interaction of Dysbindin with the AP-3 complex via its $\mu$ subunit," Neurochemistry International, vol. 54, no. 7, pp. 431-438, 2009.

[99] A. E. Deconinck, A. C. Potter, J. M. Tinsley, et al., "Postsynaptic abnormalities at the neuromuscular junctions of utrophin-deficient mice," Journal of Cell Biology, vol. 136, no. 4, pp. 883-894, 1997.

[100] R. M. Grady, J. P. Merlie, and J. R. Sanes, "Subtle neuromuscular defects in utrophin-deficient mice," Journal of Cell Biology, vol. 136, no. 4, pp. 871-882, 1997.

[101] M. E. Adams, N. Kramarcy, S. P. Krall, et al., "Absence of $\alpha$-syntrophin leads to structurally aberrant neuromuscular synapses deficient in utrophin," Journal of Cell Biology, vol. 150, no. 6, pp. 1385-1398, 2000.

[102] G. B. Banks, C. Fuhrer, M. E. Adams, and S. C. Froehner, "The postsynaptic submembrane machinery at the neuromuscular junction: requirement for rapsyn and the utrophin/dystrophin-associated complex," Brain Cell Biology, vol. 32, no. 5-8, pp. 709-726, 2003.

[103] C. Jacobson, P. D. Cote, S. G. Rossi, R. L. Rotundo, and S. Carbonetto, "The dystroglycan complex is necessary for stabilization of acetylcholine receptor clusters at neuromuscular junctions and formation of the synaptic basement membrane," Journal of Cell Biology, vol. 153, no. 3, pp. 435450, 2001.

[104] M. Akaaboune, R. M. Grady, S. Turney, J. R. Sanes, and J. W. Lichtman, "Neurotransmitter receptor dynamics studied in vivo by reversible photo-unbinding of fluorescent ligands," Neuron, vol. 34, no. 6, pp. 865-876, 2002.

[105] A. K. Peter, J. L. Marshall, and R. H. Crosbie, "Sarcospan reduces dystrophic pathology: stabilization of the utrophinglycoprotein complex," Journal of Cell Biology, vol. 183, no. 3, pp. 419-427, 2008.

[106] M. F. Peters, M. E. Adams, and S. C. Froehner, "Differential association of syntrophin pairs with the dystrophin complex," Journal of Cell Biology, vol. 138, no. 1, pp. 81-93, 1997.

[107] N. R. Kramarcy and R. Sealock, "Syntrophin isoforms at the neuromuscular junction: developmental time course and differential localization," Molecular and Cellular Neurosciences, vol. 15, no. 3, pp. 262-274, 2000.

[108] C. Pastoret and A. Sebille, "mdx mice show progressive weakness and muscle deterioration with age," Journal of the Neurological Sciences, vol. 129, no. 2, pp. 97-105, 1995.

[109] R. M. Grady, D. F. Wozniak, K. K. Ohlemiller, and J. R. Sanes, "Cerebellar synaptic defects and abnormal motor behavior in mice lacking $\alpha$ - and $\beta$-dystrobrevin," Journal of Neuroscience, vol. 26, no. 11, pp. 2841-2851, 2006.

[110] C. Vaillend, J.-M. Billard, and S. Laroche, "Impaired longterm spatial and recognition memory and enhanced CA1 hippocampal LTP in the dystrophin-deficient Dmdmdx mouse," Neurobiology of Disease, vol. 17, no. 1, pp. 10-20, 2004.

[111] A. K. Sesay, M. L. Errington, L. Levita, and T. V. P. Bliss, "Spatial learning and hippocampal long-term potentiation are not impaired in mdx mice," Neuroscience Letters, vol. 211, no. 3, pp. 207-210, 1996. 
[112] C. Vaillend, J.-M. Billard, T. Claudepierre, A. Rendon, P. Dutar, and A. Ungerer, "Spatial discrimination learning and CA1 hippocampal synaptic plasticity in $\mathrm{mdx}$ and $\mathrm{mdx}(3 \mathrm{cv})$ mice lacking dystrophin gene products," Neuroscience, vol. 86, no. 1, pp. 53-66, 1998.

[113] F. Muntoni, A. Mateddu, and G. Serra, "Passive avoidance behaviour deficit in the mdx mouse," Neuromuscular Disorders, vol. 1, no. 2, pp. 121-123, 1991.

[114] C. Vaillend, A. Rendon, R. Misslin, and A. Ungerer, "Influence of dystrophin-gene mutation on $\mathrm{mdx}$ mouse behavior. I. Retention deficits at long delays in spontaneous alternation and bar-pressing tasks," Behavior Genetics, vol. 25, no. 6, pp. 569-579, 1995.

[115] C. Vaillend, A. Ungerer, and J.-M. Billard, "Facilitated NMDA receptor-mediated synaptic plasticity in the hippocampal CA1 area of dystrophin-deficient mice," Synapse, vol. 33, no. 1, pp. 59-70, 1999.

[116] C. Vaillend and A. Ungerer, "Behavioral characterization of $\mathrm{mdx} 3 \mathrm{cv}$ mice deficient in C-terminal dystrophins," Neuromuscular Disorders, vol. 9, no. 5, pp. 296-304, 1999.

[117] M. F. Mehler, K. Z. Haas, J. A. Kessler, and P. K. Stanton, "Enhanced sensitivity of hippocampal pyramidal neurons from mdx mice to hypoxia-induced loss of synaptic transmission," Proceedings of the National Academy of Sciences of the United States of America, vol. 89, no. 6, pp. 2461-2465, 1992.

[118] D. Carretta, M. Santarelli, D. Vanni, et al., "Cortical and brainstem neurons containing calcium-binding proteins in a murine model of Duchenne's muscular dystrophy: selective changes in the sensorimotor cortex," Journal of Comparative Neurology, vol. 456, no. 1, pp. 48-59, 2003.

[119] R. Miranda, C. Sebrie, J. Degrouard, et al., "Reorganization of inhibitory synapses and increased PSD length of perforated excitatory synapses in hippocampal area CA1 of dystrophindeficient mdx mice," Cerebral Cortex, vol. 19, no. 4, pp. 876$888,2009$.

[120] J. L. Anderson, S. I. Head, and J. W. Morley, "Longterm depression is reduced in cerebellar Purkinje cells of dystrophin-deficient mdx mice," Brain Research, vol. 1019, no. 1-2, pp. 289-292, 2004.

[121] J. L. Anderson, J. W. Morley, and S. I. Head, "Enhanced homosynaptic LTD in cerebellar Purkinje cells of the dystrophic mdx mouse," Muscle and Nerve, vol. 41, no. 3, pp. 329-334, 2010.

[122] J. E. Anderson, "A role for nitric oxide in muscle repair: nitric oxide-mediated activation of muscle satellite cells," Molecular Biology of the Cell, vol. 11, no. 5, pp. 1859-1874, 2000.

[123] M. G. D'Angelo and N. Bresolin, "Cognitive impairment in neuromuscular disorders," Muscle and Nerve, vol. 34, no. 1, pp. 16-33, 2006.

[124] I. Brunig, A. Suter, I. Knuesel, B. Luscher, and J.-M. Fritschy, "GABAergic terminals are required for postsynaptic clustering of dystrophin but not of GABAA receptors and gephyrin," Journal of Neuroscience, vol. 22, no. 12, pp. 48054813, 2002.

[125] S. Levi, R. M. Grady, M. D. Henry, K. P. Campbell, J. R. Sanes, and A. M. Craig, "Dystroglycan is selectively associated with inhibitory GABAergic synapses but is dispensable for their differentiation," Journal of Neuroscience, vol. 22, no. 11, pp. 4274-4285, 2002.

[126] I. Knuesel, M. Mastrocola, R. A. Zuellig, B. Bornhauser, M. C. Schaub, and J.-M. Fritschy, "Altered synaptic clustering of GABAA receptors in mice lacking dystrophin ( $\mathrm{mdx}$ mice),"
European Journal of Neuroscience, vol. 11, no. 12, pp. 44574462, 1999.

[127] J.-M. Fritschy, C. Schweizer, I. Brunig, and B. Luscher, "Preand post-synaptic mechanisms regulating the clustering of type A $\gamma$-aminobutyric acid receptors (GABAA receptors)," Biochemical Society Transactions, vol. 31, no. 4, pp. 889-892, 2003.

[128] A. M. Craig and Y. Kang, "Neurexin-neuroligin signaling in synapse development," Current Opinion in Neurobiology, vol. 17, no. 1, pp. 43-52, 2007.

[129] I. Knuesel, R. A. Zuellig, M. C. Schaub, and J.-M. Fritschy, "Alterations in dystrophin and utrophin expression parallel the reorganization of GABAergic synapses in a mouse model of temporal lobe epilepsy," European Journal of Neuroscience, vol. 13, no. 6, pp. 1113-1124, 2001.

[130] J. L. Anderson, S. I. Head, and J. W. Morley, "Altered inhibitory input to Purkinje cells of dystrophin-deficient mice," Brain Research, vol. 982, no. 2, pp. 280-283, 2003.

[131] C. Vaillend and J.-M. Billard, "Facilitated CA1 hippocampal synaptic plasticity in dystrophin-deficient mice: role of GABAA receptors?" Hippocampus, vol. 12, no. 6, pp. 713$717,2002$.

[132] S. L. L. Kueh, S. I. Head, and J. W. Morley, "GABA receptor expression and inhibitory post-synaptic currents in cerebellar Purkinje cells in dystrophin-deficient mdx mice," Clinical and Experimental Pharmacology and Physiology, vol. 35, no. 2, pp. 207-210, 2008.

[133] L. Graciotti, A. Minelli, D. Minciacchi, A. Procopio, and G. Fulgenzi, "GABAergic miniature spontaneous activity is increased in the CA1 hippocampal region of dystrophic $\mathrm{mdx}$ mice," Neuromuscular Disorders, vol. 18, no. 3, pp. 220-226, 2008.

[134] C. Del Tongo, D. Carretta, G. Fulgenzi, C. Catini, and D. Minciacchi, "Parvalbumin-positive GABAergic interneurons are increased in the dorsal hippocampus of the dystrophic mdx mouse," Acta Neuropathologica, vol. 118, no. 6, pp. 803812, 2009.

[135] Y. Yoshihara, H. Onodera, K. Iinuma, and Y. Itoyama, "Abnormal kainic acid receptor density and reduced seizure susceptibility in dystrophin-deficient mdx mice," Neuroscience, vol. 117, no. 2, pp. 391-395, 2003.

[136] G. De Sarro, G. F. Ibbadu, R. Marra, et al., "Seizure susceptibility to various convulsant stimuli in dystrophindeficient mdx mice," Neuroscience Research, vol. 50, no. 1, pp. 37-44, 2004.

[137] R. Coccurello, C. Castellano, P. Paggi, A. Mele, and A. Oliverio, "Genetically dystrophic $\mathrm{mdx} / \mathrm{mdx}$ mice exhibit decreased response to nicotine in passive avoidance," NeuroReport, vol. 13, no. 9, pp. 1219-1222, 2002.

[138] A. Del Signore, C. Gotti, M. E. De Stefano, M. Moretti, and P. Paggi, "Dystrophin stabilizes $\alpha 3$ - but not $\alpha 7$-containing nicotinic acetylcholine receptor subtypes at the postsynaptic apparatus in the mouse superior cervical ganglion," Neurobiology of Disease, vol. 10, no. 1, pp. 54-66, 2002.

[139] B. Nico, A. Frigeri, G. P. Nicchia, et al., "Severe alterations of endothelial and glial cells in the blood-brain barrier of dystrophic mdx mice," Glia, vol. 42, no. 3, pp. 235-251, 2003.

[140] B. Nico, G. P. Nicchia, A. Frigeri, et al., "Altered blood-brain barrier development in dystrophic MDX mice," Neuroscience, vol. 125, no. 4, pp. 921-935, 2004.

[141] B. Nico, P. Corsi, R. Ria, et al., "Increased matrixmetalloproteinase- 2 and matrix-metalloproteinase- 9 expression in the brain of dystrophic mdx mouse," Neuroscience, vol. 140 , no. 3 , pp. 835-848, 2006. 
[142] B. Nico, D. Mangieri, E. Crivellato, et al., "HIF activation and VEGF overexpression are coupled with ZO-1 upphosphorylation in the brain of dystrophic MDX mouse," Brain Pathology, vol. 17, no. 4, pp. 399-406, 2007.

[143] A. Baydur, I. Gilgoff, W. Prentice, M. Carlson, and D. A. Fischer, "Decline in respiratory function and experience with long-term assisted ventilation in advanced Duchenne's muscular dystrophy," Chest, vol. 97, no. 4, pp. 884-889, 1990.

[144] R. Sarig, V. Mezger-Lallemand, I. Gitelman, et al., "Targeted inactivation of Dp71, the major non-muscle product of the DMD gene: differential activity of the Dp71 promoter during development," Human Molecular Genetics, vol. 8, no. 1, pp. $1-10,1999$.

[145] C. Vaillend, R. Poirier, and S. Laroche, "Genes, plasticity and mental retardation," Behavioural Brain Research, vol. 192, no. 1, pp. 88-105, 2008.

[146] M. Amiry-Moghaddam, R. Xue, F. M. Haug, et al., "Alpha-syntrophin deletion removes the perivascular but not endothelial pool of aquaporin-4 at the blood-brain barrier and delays the development of brain edema in an experimental model of acute hyponatremia," FASEB Journal, vol. 18, no. 3, pp. 542-544, 2004.

[147] Z. Vajda, M. Pedersen, E.-M. Fuchtbauer, et al., "Delayed onset of brain edema and mislocalization of aquaporin-4 in dystrophin-null transgenic mice," Proceedings of the National Academy of Sciences of the United States of America, vol. 99, no. 20, pp. 13131-13136, 2002.

[148] G. P. Nicchia, A. Rossi, U. Nudel, M. Svelto, and A. Frigeri, "Dystrophin-dependent and -independent AQP4 pools are expressed in the mouse brain," Glia, vol. 56, no. 8, pp. 869$876,2008$.

[149] H. Hibino, A. Fujita, K. Iwai, M. Yamada, and Y. Kurachi, "Differential assembly of inwardly rectifying $\mathrm{K}+$ channel subunits, Kir4.1 and Kir5.1, in brain astrocytes," Journal of Biological Chemistry, vol. 279, no. 42, pp. 44065-44073, 2004.

[150] N. C. Connors, M. E. Adams, S. C. Froehner, and P. Kofuji, "The potassium channel Kir4.1 associates with the dystrophin-glycoprotein complex via $\alpha$-syntrophin in glia," Journal of Biological Chemistry, vol. 279, no. 27, pp. 2838728392, 2004.

[151] E. Guadagno and H. Moukhles, "Laminin-induced aggregation of the inwardly rectifying potassium channel, Kir4.1, and the water-permeable channel, AQP4, via a dystroglycancontaining complex in astrocytes," Glia, vol. 47, no. 2, pp. 138-149, 2004.

[152] A. Sene, R. Tadayoni, T. Pannicke, et al., "Functional implication of Dp71 in osmoregulation and vascular permeability of the retina," PloS One, vol. 4, no. 10, article e7329, 2009.

[153] C. Dalloz, R. Sarig, P. Fort, et al., "Targeted inactivation of dystrophin gene product Dp71: phenotypic impact in mouse retina," Human Molecular Genetics, vol. 12, no. 13, pp. 15431554, 2003.

[154] R. Benabdesselam, A. Sene, D. Raison, et al., "A deficit of brain dystrophin 71 impairs hypothalamic osmostat," Journal of Neuroscience Research, vol. 88, no. 2, pp. 324-334, 2010.

[155] S. Saadoun, M. J. Tait, A. Reza, et al., "AQP4 gene deletion in mice does not alter blood-brain barrier integrity or brain morphology," Neuroscience, vol. 161, no. 3, pp. 764-772, 2009.

[156] D. C. Gorecki, K. Lukasiuk, A. Szklarczyk, and L. Kaczmarek, "Kainate-evoked changes in dystrophin messenger RNA levels in the rat hippocampus," Neuroscience, vol. 84, no. 2, pp. 467-477, 1998.
[157] M. Ceccarini, P. Macioce, B. Panetta, and T. C. Petrucci, "Expression of dystrophin-associated proteins during neuronal differentiation of P19 embryonal carcinoma cells," Neuromuscular Disorders, vol. 12, no. 1, pp. 36-48, 2002.

[158] J. Cerna, D. Cerecedo, A. Ortega, et al., "Dystrophin Dp71f associates with the $\beta 1$-integrin adhesion complex to modulate PC12 cell adhesion," Journal of Molecular Biology, vol. 362, no. 5, pp. 954-965, 2006.

[159] A. E. Deconinck, J. A. Rafael, J. A. Skinner, et al., "Utrophindystrophin-deficient mice as a model for Duchenne muscular dystrophy," Cell, vol. 90, no. 4, pp. 717-727, 1997.

[160] R. M. Grady, H. Teng, M. C. Nichol, J. C. Cunningham, R. S. Wilkinson, and J. R. Sanest, "Skeletal and cardiac myopathies in mice lacking utrophin and dystrophin: a model for Duchenne muscular dystrophy," Cell, vol. 90, no. 4, pp. 729-738, 1997.

[161] I. Knuesel, V. Riban, R. A. Zuellig, et al., "Increased vulnerability to kainate-induced seizures in utrophin-knockout mice," European Journal of Neuroscience, vol. 15, no. 9, pp. 1474-1484, 2002.

[162] K. Culligan, L. Glover, P. Dowling, and K. Ohlendieck, "Brain dystrophin-glycoprotein complex: persistent expression of beta-dystroglycan, impaired oligomerization of Dp71 and up-regulation of utrophins in animal models of muscular dystrophy," BMC Cell Biology, vol. 2, article 2, 2001.

[163] K. Hnia, S. Tuffery-Giraud, M. Vermaelen, et al., "Pathological pattern of Mdx mice diaphragm correlates with gradual expression of the short utrophin isoform Up71," Biochimica et Biophysica Acta, vol. 1762, no. 3, pp. 362-372, 2006.

[164] S. Bogdanovich, K. J. Perkins, T. O. B. Krag, and T. S. Khurana, "Therapeutics for Duchenne muscular dystrophy: current approaches and future directions," Journal of Molecular Medicine, vol. 82, no. 2, pp. 102-115, 2004.

[165] C. Angelini, E. Pegoraro, E. Turella, M. T. Intino, A. Pini, and C. Costa, "Deflazacort in Duchenne dystrophy: study of longterm effect," Muscle and Nerve, vol. 17, no. 4, pp. 386-391, 1994.

[166] M. D. Bonifati, G. Ruzza, P. Bonometto, et al., "A multicenter, double-blind, randomized trial of deflazacort versus prednisone in duchenne muscular dystrophy," Muscle and Nerve, vol. 23, no. 9, pp. 1344-1347, 2000.

[167] T. A. Partridge, J. E. Morgan, G. R. Coulton, E. P. Hoffman, and L. M. Kunkel, "Conversion of mdx myofibres from dystrophin-negative to -positive by injection of normal myoblasts," Nature, vol. 337, no. 6203, pp. 176-179, 1989.

[168] B. Péault, M. Rudnicki, Y. Torrente, et al., "Stem and progenitor cells in skeletal muscle development, maintenance, and therapy," Molecular Therapy, vol. 15, no. 5, pp. 867-877, 2007.

[169] E. Gussoni, R. R. Bennett, K. R. Muskiewicz, et al., "Longterm persistence of donor nuclei in a Duchenne muscular dystrophy patient receiving bone marrow transplantation," Journal of Clinical Investigation, vol. 110, no. 6, pp. 807-814, 2002.

[170] S. Ebihara, G.-H. Guibinga, R. Gilbert, et al., "Differential effects of dystrophin and utrophin gene transfer in immunocompetent muscular dystrophy $(\mathrm{mdx})$ mice," Physiological Genomics, vol. 3, no. 3, pp. 133-144, 2000.

[171] G. M. Smythe, S. I. Hodgetts, and M. D. Grounds, "Problems and solutions in myoblast transfer therapy," Journal of Cellular and Molecular Medicine, vol. 5, no. 1, pp. 33-47, 2001. 
[172] D. Cerecedo, R. Mondragon, A. Candelario, et al., "Utrophins compensate for Dp71 absence in $\mathrm{mdx} 3 \mathrm{cv}$ in adhered platelets," Blood Coagulation and Fibrinolysis, vol. 19, no. 1, pp. 39-47, 2008.

[173] K. P. Campbell and R. H. Crosbie, "Utrophin to the rescue," Nature, vol. 384, no. 6607, pp. 308-309, 1996.

[174] J. M. Tinsley, A. C. Potter, S. R. Phelps, R. Fisher, J. I. Trickett, and K. E. Davies, "Amelioration of the dystrophic phenotype of mdx mice using a truncated utrophin transgene," Nature, vol. 384, no. 6607, pp. 349-353, 1996.

[175] G. L. Odom, P. Gregorevic, J. M. Allen, E. Finn, and J. S. Chamberlain, "Microutrophin delivery through rAAV6 increases lifespan and improves muscle function in dystrophic dystrophin/Utrophin-deficient mice," Molecular Therapy, vol. 16, no. 9, pp. 1539-1545, 2008.

[176] E. Chaubourt, P. Fossier, G. Baux, C. Leprince, M. Israel, and S. De La Porte, "Nitric oxide and L-arginine cause an accumulation of utrophin at the sarcolemma: a possible compensation for dystrophin loss in Duchenne muscular dystrophy," Neurobiology of Disease, vol. 6, no. 6, pp. 499-507, 1999.

[177] E. R. Barton, L. Morris, M. Kawana, L. T. Bish, and T. Toursel, "Systemic administration of L-arginine benefits mdx skeletal muscle function," Muscle and Nerve, vol. 32, no. 6, pp. 751760, 2005.

[178] V. Voisin, C. Sebrie, S. Matecki, et al., "L-arginine improves dystrophic phenotype in mdx mice," Neurobiology of Disease, vol. 20, no. 1, pp. 123-130, 2005.

[179] F. Benabdellah, A. Seyer, L. Quinton, D. Touboul, A. Brunelle, and O. Laprévote, "Mass spectrometry imaging of rat brain sections: nanomolar sensitivity with MALDI versus nanometer resolution by TOF-SIMS," Analytical and Bioanalytical Chemistry, vol. 396, no. 1, pp. 151-162, 2010.

[180] K. Hnia, J. Gayraud, G. Hugon, et al., "L-arginine decreases inflammation and modulates the nuclear factor- $\kappa \mathrm{B} /$ matrix metalloproteinase cascade in Mdx muscle fibers," American Journal of Pathology, vol. 172, no. 6, pp. 1509-1519, 2008.

[181] D. Chazalette, K. Hnia, F. Rivier, G. Hugon, and D. Mornet, " $\alpha 7 \mathrm{~B}$ integrin changes in $\mathrm{mdx}$ mouse muscles after Larginine administration," FEBS Letters, vol. 579, no. 5, pp. 1079-1084, 2005.

[182] B. Deng, D. Glanzman, and J. G. Tidball, "Nitric oxide generated by muscle corrects defects in hippocampal neurogenesis and neural differentiation caused by muscular dystrophy," Journal of Physiology, vol. 587, no. 8, pp. 1769-1778, 2009.

[183] T. S. Khurana, A. G. Rosmarin, J. Shang, T. O. B. Krag, S. Das, and S. Gammeltoft, "Activation of utrophin promoter by heregulin via the ets-related transcription factor complex GA-binding protein $\alpha / \beta$," Molecular Biology of the Cell, vol. 10, no. 6, pp. 2075-2086, 1999.

[184] T. O. B. Krag, S. Bogdanovich, C. J. Jensen, et al., "Heregulin ameliorates the dystrophic phenotype in mdx mice," Proceedings of the National Academy of Sciences of the United States of America, vol. 101, no. 38, pp. 13856-13860, 2004.

[185] A. J. Kastin, V. Akerstrom, and W. Pan, "Neuregulin-1- $\beta 1$ enters brain and spinal cord by receptor-mediated transport," Journal of Neurochemistry, vol. 88, no. 4, pp. 965-970, 2004.

[186] J. V. Chakkalakal, M.-A. Harrison, S. Carbonetto, E. Chin, R. N. Michel, and B. J. Jasmin, "Stimulation of calcineurin signaling attenuates the dystrophic pathology in mdx mice," Human Molecular Genetics, vol. 13, no. 4, pp. 379-388, 2004.
[187] P. Miura and B. J. Jasmin, "Utrophin upregulation for treating Duchenne or Becker muscular dystrophy: how close are we?" Trends in Molecular Medicine, vol. 12, no. 3, pp. 122129, 2006.

[188] S. J. G. St-Pierre, J. V. Chakkalakal, S. M. Kolodziejczyk, J. C. Knudson, B. J. Jasmin, and L. A. Megeney, "Glucocorticoid treatment alleviates dystrophic myofiber pathology by activation of the calcineurin/NF-AT pathway," FASEB Journal, vol. 18, no. 15, pp. 1937-1939, 2004.

[189] A. O. Gramolini and B. J. Jasmin, "Expression of the utrophin gene during myogenic differentiation," Nucleic Acids Research, vol. 27, no. 17, pp. 3603-3609, 1999.

[190] P. Miura, J. V. Chakkalakal, L. Boudreault, et al., "Pharmacological activation of $\operatorname{PPAR} \beta / \delta$ stimulates utrophin A expression in skeletal muscle fibers and restores sarcolemmal integrity in mature mdx mice," Human Molecular Genetics, vol. 18, no. 23, pp. 4640-4649, 2009.

[191] S. F. Nelson, R. H. Crosbie, M. C. Miceli, and M. J. Spencer, "Emerging genetic therapies to treat Duchenne muscular dystrophy," Current Opinion in Neurology, vol. 22, no. 5, pp. 532-538, 2009.

[192] P. Dunant, M. C. Walter, G. Karpati, and H. Lochmuller, "Gentamicin fails to increase dystrophin expression in dystrophin-deficient muscle," Muscle and Nerve, vol. 27, no. 5, pp. 624-627, 2003.

[193] A. De Luca, B. Nico, J.-F. Rolland, et al., "Gentamicin treatment in exercised mdx mice: identification of dystrophinsensitive pathways and evaluation of efficacy in work-loaded dystrophic muscle," Neurobiology of Disease, vol. 32, no. 2, pp. 243-253, 2008.

[194] K. R. Wagner, S. Hamed, D. W. Hadley, et al., "Gentamicin treatment of Duchenne and Becker muscular dystrophy due to nonsense mutations," Annals of Neurology, vol. 49, no. 6, pp. 706-711, 2001.

[195] L. Du, R. Damoiseaux, S. Nahas, et al., "Nonaminoglycoside compounds induce readthrough of nonsense mutations," Journal of Experimental Medicine, vol. 206, no. 10, pp. 22852297, 2009.

[196] E. M. Welch, E. R. Barton, J. Zhuo, et al., "PTC124 targets genetic disorders caused by nonsense mutations," Nature, vol. 447, no. 7140, pp. 87-91, 2007.

[197] S. Hirawat, E. M. Welch, G. L. Elfring, et al., "Safety, tolerability, and pharmacokinetics of PTC124, a nonaminoglycoside nonsense mutation suppressor, following singleand multiple-dose administration to healthy male and female adult volunteers," Journal of Clinical Pharmacology, vol. 47, no. 4, pp. 430-444, 2007.

[198] A. Aartsma-Rus, I. Fokkema, J. Verschuuren, et al., "Theoretic applicability of antisense-mediated exon skipping for Duchenne muscular dystrophy mutations," Human Mutation, vol. 30, no. 3, pp. 293-299, 2009.

[199] J. C. van Deutekom, A. A. Janson, I. B. Ginjaar, et al., "Local dystrophin restoration with antisense oligonucleotide PRO051," The New England Journal of Medicine, vol. 357, no. 26, pp. 2677-2686, 2007.

[200] M. Kinali, V. Arechavala-Gomeza, L. Feng, et al., "Local restoration of dystrophin expression with the morpholino oligomer AVI-4658 in Duchenne muscular dystrophy: a single-blind, placebo-controlled, dose-escalation, proof-ofconcept study," The Lancet Neurology, vol. 8, no. 10, pp. 918928, 2009.

[201] H. M. Moulton, B. Wu, N. Jearawiriyapaisarn, P. Sazani, Q. L. Lu, and R. Kole, "Peptide-morpholino conjugate: a promising therapeutic for duchenne muscular dystrophy," 
Annals of the New York Academy of Sciences, vol. 1175, pp. 55-60, 2009.

[202] A. Goyenvalle, A. Vulin, F. Fougerousse, et al., "Rescue of dystrophic muscle through U7 snRNA-mediated exon skipping," Science, vol. 306, no. 5702, pp. 1796-1799, 2004.

[203] A. Goyenvalle, A. Babbs, G.-J. B. van Ommen, L. Garcia, and K. E. Davies, "Enhanced exon-skipping induced by U7 snRNA carrying a splicing silencer sequence: promising tool for DMD therapy," Molecular Therapy, vol. 17, no. 7, pp. 1234-1240, 2009.

[204] C. Wang, C.-M. Wang, K. R. Clark, and T. J. Sferra, "Recombinant AAV serotype 1 transduction efficiency and tropism in the murine brain," Gene Therapy, vol. 10, no. 17, pp. 1528-1534, 2003.

[205] C. Burger, O. S. Gorbatyuk, M. J. Velardo, et al., "Recombinant AAV viral vectors pseudotyped with viral capsids from serotypes 1, 2, and 5 display differential efficiency and cell tropism after delivery to different regions of the central nervous system," Molecular Therapy, vol. 10, no. 2, pp. 302317, 2004. 

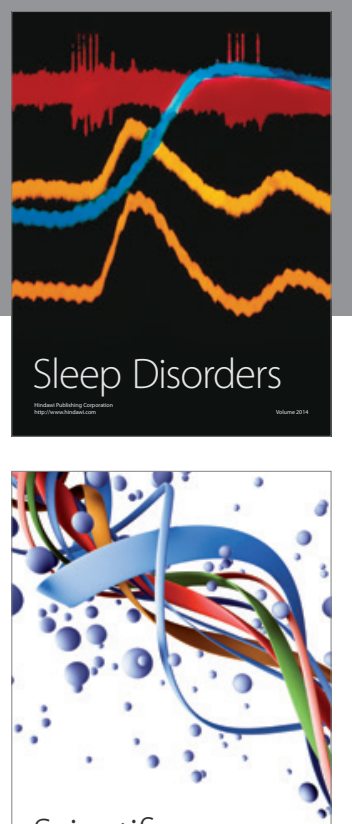

Scientifica
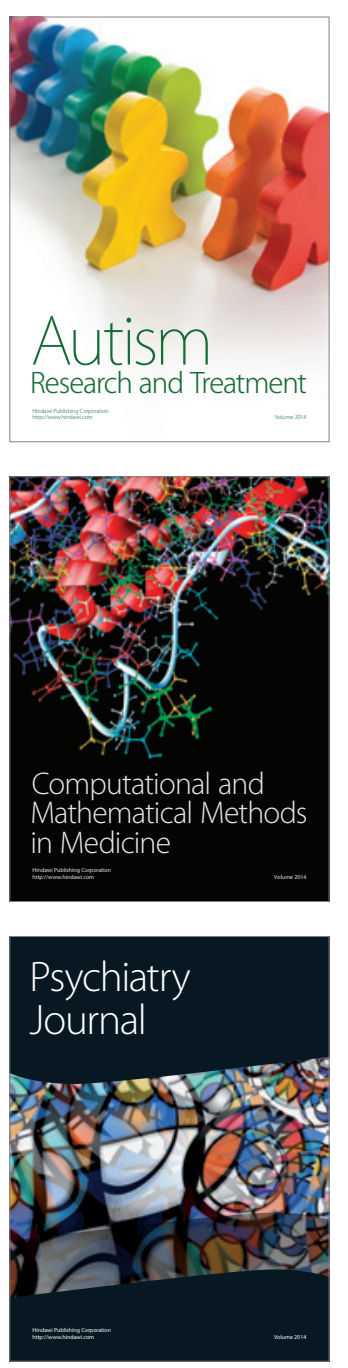
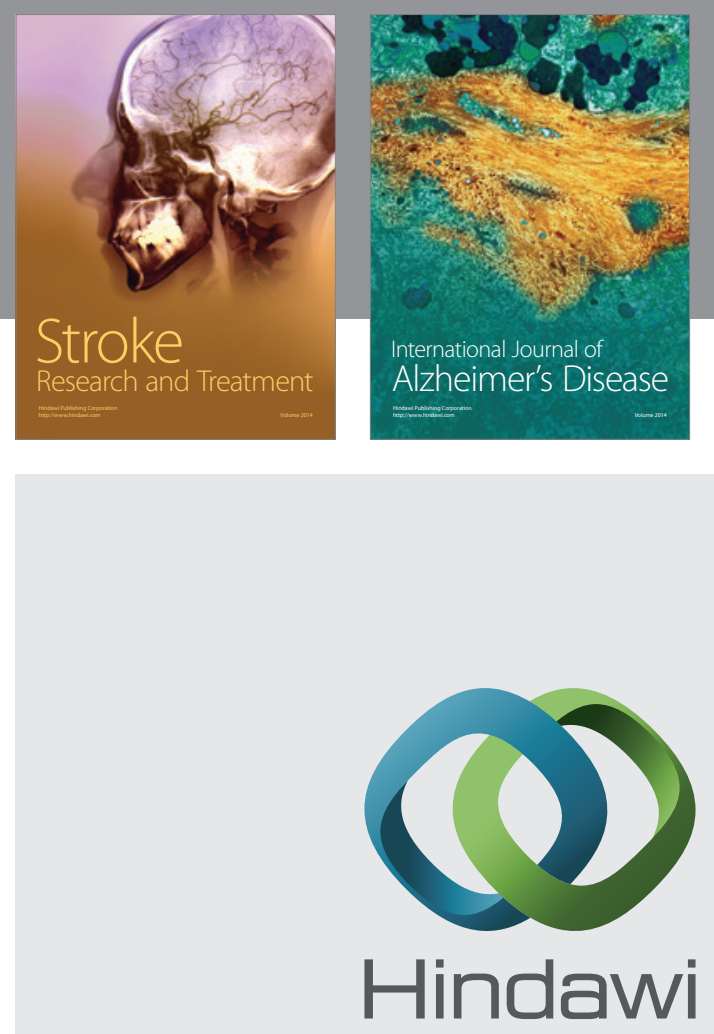

Submit your manuscripts at

http://www.hindawi.com
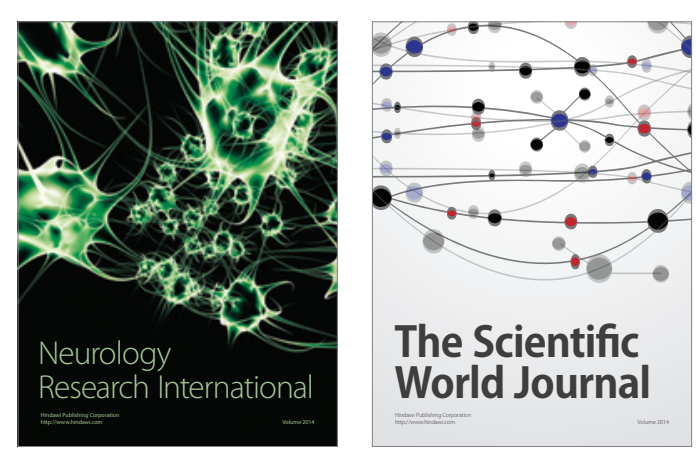

The Scientific World Journal

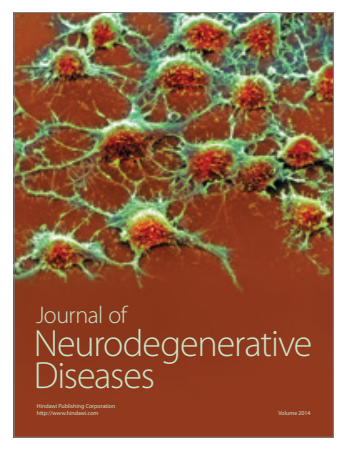

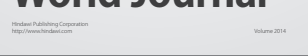

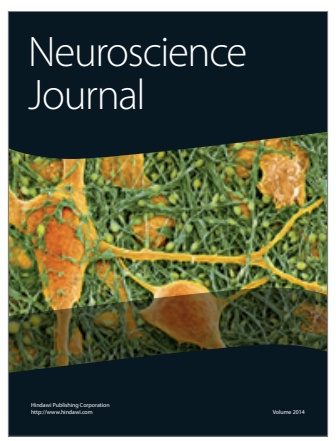

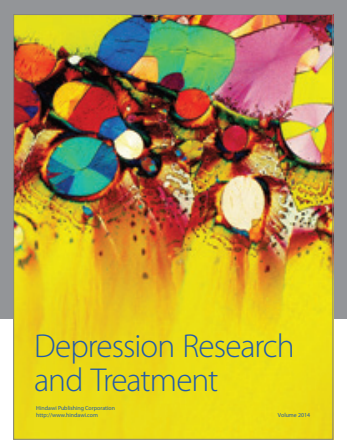
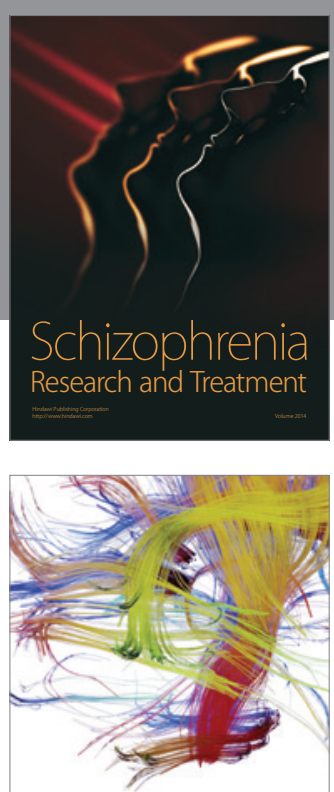

Brain Science

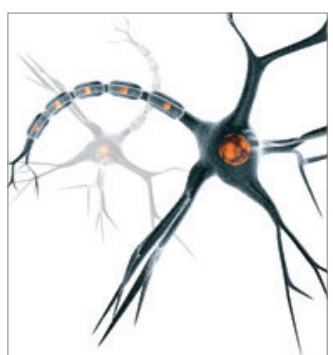

Neural Plasticity
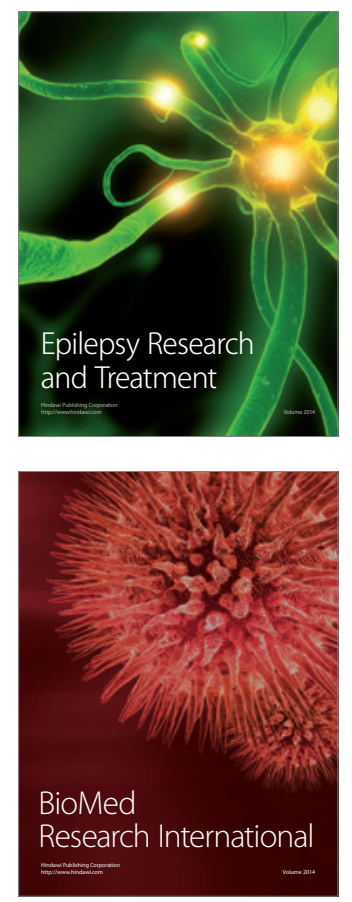

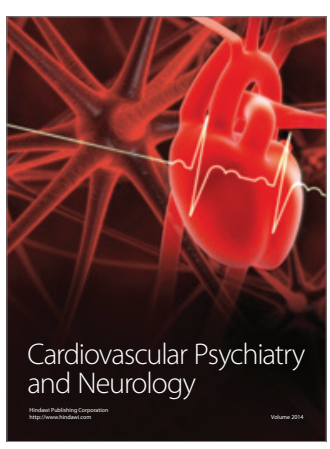

Parkinson's

Disease
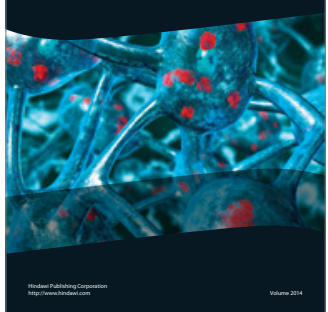